OPEN ACCESS

Edited by:

Lavinia Alberi,

SICHH, Switzerland

Reviewed by:

Bin Xu,

North Carolina Central University,

United States

Laetitia Lemoine,

Karolinska Institutet (KI), Sweden

*Correspondence:

Ruiqing $\mathrm{Ni}$

ruiqing.ni@uzh.ch

Received: 02 August 2021 Accepted: 17 November 2021

Published: 03 January 2022

Citation:

Ni R and Nitsch RM (2022)

Recent Developments in Positron

Emission Tomography Tracers

for Proteinopathies Imaging

in Dementia.

Front. Aging Neurosci. 13:751897.

doi: 10.3389/fnagi.2021.751897

\section{Recent Developments in Positron Emission Tomography Tracers for Proteinopathies Imaging in Dementia}

\author{
Ruiqing Ni1,2* and Roger M. Nitsch ${ }^{1}$ \\ 1 Institute for Regenerative Medicine, University of Zurich, Zurich, Switzerland, ${ }^{2}$ Institute for Biomedical Engineering, ETH \& \\ University of Zurich, Zurich, Switzerland
}

An early detection and intervention for dementia represent tremendous unmet clinical needs and priorities in society. A shared feature of neurodegenerative diseases causing dementia is the abnormal accumulation and spreading of pathological protein aggregates, which affect the selective vulnerable circuit in a disease-specific pattern. The advancement in positron emission tomography (PET) biomarkers has accelerated the understanding of the disease mechanism and development of therapeutics for Alzheimer's disease and Parkinson's disease. The clinical utility of amyloid- $\beta$ PET and the clinical validity of tau PET as diagnostic biomarker for Alzheimer's disease continuum have been demonstrated. The inclusion of biomarkers in the diagnostic criteria has introduced a paradigm shift that facilitated the early and differential disease diagnosis and impacted on the clinical management. Application of disease-modifying therapy likely requires screening of patients with molecular evidence of pathological accumulation and monitoring of treatment effect assisted with biomarkers. There is currently still a gap in specific 4-repeat tau imaging probes for 4-repeat tauopathies and $\alpha$-synuclein imaging probes for Parkinson's disease and dementia with Lewy body. In this review, we focused on recent development in molecular imaging biomarkers for assisting the early diagnosis of proteinopathies (i.e., amyloid- $\beta$, tau, and $\alpha$-synuclein) in dementia and discussed future perspectives.

\footnotetext{
Keywords: amyloid- $\beta$, tau, $\alpha$-synclein, positron emission tomography (PET), Alzheimer's disease, Parkinson's disease, Lewy bodies, frontotemporal dementia (FTD)
}

\section{INTRODUCTION}

Today, nearly 50 million worldwide live with dementia. This number is projected to reach 152 million in 2050 as the population ages (Bhatt et al., 2019; Cummings et al., 2021b). An early detection and intervention for dementia represent tremendous unmet clinical needs and priorities in the aging societies. Neurodegenerative diseases, including Alzheimer's disease (AD), Parkinson's disease (PD), frontotemporal dementia (FTD), and dementia with Lewy bodies (DLB), are the most common causes of dementia. In these diseases, the abnormal accumulation of aggregates of the pathological protein activates a cascade of biochemical changes and affects the selective vulnerable circuit in a disease-specific pattern (Pievani et al., 2014; Bang et al., 2015; Goedert, 2015; De Strooper and Karran, 2016; Jucker and Walker, 2018; Soto and Pritzkow, 2018; Park et al., 2020). AD is pathologically hallmarked by amyloid- $\beta$ (A $\beta$ ) plaque, neurofibrillary tangle (NFT), 
and neuronal loss (Knopman et al., 2021; Scheltens et al., 2021). Clinically, $A D$ is characterized by the progressive loss of memory and cognitive functions, gradually affecting the daily life of patients. In vivo imaging studies in $\mathrm{AD}$ have shown that molecular changes in the brain precede the occurrence of clinical symptoms of cognitive decline by a long period, up to 15 years (Palmqvist et al., 2021). FTD includes a spectrum of tauopathy diseases, including corticobasal disease (CBD), progressive supranuclear palsy (PSP), and Pick's disease (Spillantini and Goedert, 2013), clinically characterized by progressive executive, behavioral, or language dysfunctions depending on the disease types (Spillantini and Goedert, 2013). DLB, PD, and multiple system atrophy (MSA) are pathologically characterized by the appearance of Lewy bodies and Lewy neurites, composed of aggregated $\alpha$-synuclein fibrils (Fares et al., 2021). The loss of dopaminergic neurons in the substantia nigra is the major pathological hallmark of PD (Poewe et al., 2017). The clinical diagnosis of PD is based on the motor dysfunction symptoms, including bradykinesia, rigidity, and resting tremor due to the nigrostriatal degeneration. Overlapping clinical symptoms and comorbidities in different diseases impose challenges on the accurate disease diagnosis, especially at a prodromal or early disease stage (Irwin et al., 2013). For example, the clinical symptoms in PD overlap with that in MSA and PSP to a certain extent (Politis, 2014). AD overlaps in the symptom or in pathological features with vascular dementia, FTD, and DLB (Knopman et al., 2021). Thus, a highly specific biomarker or combinations of biomarkers for increasing the diagnostic accuracy and enabling optimal treatment strategy are highly desired. In this review, we focused on the recent developments in positron emission tomography (PET) tracers for the detection of proteinopathies (i.e., $\mathrm{A} \beta$, tau, and $\alpha$-synuclein) in neurodegenerative diseases.

\section{POSITRON EMISSION TOMOGRAPHY FOR PROTEINOPATHIES IN NEURODEGENERATIVE DISEASES}

The advances in molecular imaging using PET, structural and functional imaging using magnetic resonance imaging, cerebrospinal fluid assays for detecting disease pathological hallmarks have facilitated the early and differential diagnosis and clinical management in $\mathrm{AD}$, as well as the understanding of the disease mechanism and development of therapeutics (Sevigny et al., 2016; Crunkhorn, 2017; Boxer et al., 2019; Rabinovici et al., 2019; Chételat et al., 2021; Hansson, 2021). $\left[{ }^{18} \mathrm{~F}\right]$ fluorodeoxyglucose (FDG)-PET has been used for detecting the cerebral glucose hypometabolism in diseasespecific brain regions in patients with $\mathrm{AD}$, FTD (Foster et al., 2007; Chételat et al., 2020), and idiopathic PD and atypical parkinsonism associated with dementia improving the diagnostic accuracy (Walker et al., 2018). There is a rapid advancement in recent 20 years in the development of specific PET tracers for pathological proteinopathies, neuroinflammation, and synaptic density markers in neurodegenerative diseases. Several prerequisites need to be fulfilled for an ideal PET tracer, including low molecular weight, sensitivity, specificity (i.e., low off-target binding), high affinity, moderate lipophilicity, solubility, blood-brain barrier entrance (i.e., sufficient brain uptake), reversible binding property, and pharmacokinetics, as well as no radiolabeled metabolites in the brain (Pike, 2009).

\section{Amyloid- $\beta$ Imaging}

Amyloid- $\beta$ is produced by proteolytic processing of the amyloid precursor protein on the neurons and glial cells. An imbalance between the production and clearance of $A \beta$ leads to its abnormal cerebral accumulation (i.e., accumulation of oligomers, protofibrils, fibrils, and amyloid plaques), which plays a central role in the pathogenesis of $\mathrm{AD}$ both in animal models and in patients (Lesné et al., 2006; Haass and Selkoe, 2007; Lambert et al., 2007; Shankar et al., 2008; Selkoe and Hardy, 2016). The spread of $A \beta$ follows a specific pattern, starting from neocortical regions to regions that receive neuronal projections and later to subcortical regions such as the striatum and the cerebellum (Thal et al., 2002). Using amyloid PET imaging combined with a functional MRI, the earliest accumulation of $\mathrm{A} \beta$ is found within the default mode network and, concurrently, affects the brain connectivity (Altmann et al., 2015; Palmqvist et al., 2017; Sepulcre et al., 2017; Hanseeuw et al., 2019; Rabinovici et al., 2019; Vogel et al., 2020). Amyloid PET tracers detect the $\beta$-sheet structures and are mainly benzothiazole and benzoxazole derivatives (Table 1; Klunk et al., 2004; Rowe et al., 2008; Furukawa et al., 2009; Nelissen et al., 2009; Nyberg et al., 2009; Hostetler et al., 2011; Cselenyi et al., 2012; Rodriguez-Vieitez et al., 2015; Sehlin et al., 2016; Grimmer et al., 2020; Meier et al., 2021; Ni, 2021; Ni et al., 2021). Among these tracers, three have been approved by Food and Drug Administration (FDA) and European Medicines Agency for clinical usage, namely, $\left[{ }^{18} \mathrm{~F}\right]$ flutemetamol (Vizamyl), $\left[{ }^{18} \mathrm{~F}\right]$ florbetapir (Amyvid), and $\left[{ }^{18} \mathrm{~F}\right]$ florbetaben (Neuraceq) (Clark et al., 2011; Curtis et al., 2015; Sabri et al., 2015). PET studies using amyloid probes $\left[{ }^{11} \mathrm{C}\right] \mathrm{PiB},\left[{ }^{18} \mathrm{~F}\right]$ flutemetamol, $\left[{ }^{18} \mathrm{~F}\right]$ florbetapir, $\left[{ }^{18} \mathrm{~F}\right]$ florbetaben, and $\left[{ }^{18} \mathrm{~F}\right]$ flutafuranol (AZD4694) have demonstrated higher cortical fibrillar $A \beta$ loads in patients with mild cognitive impairment and $\mathrm{AD}$ compared with those in healthy controls (Klunk et al., 2005; Clark et al., 2011; Curtis et al., 2015; Sabri et al., 2015; Jack et al., 2018; Wolk et al., 2018). A robust in vivo congruence between aforementioned tracers and an in vivo postmortem correlation have been demonstrated in the human brain (Villemagne et al., 2012; Rowe et al., 2013; Ni et al., 2017, 2021; Su et al., 2019; Ikonomovic et al., 2020). It is noted that $\mathrm{A} \beta$ deposits are detected in the non-demented control, with the incidence associating with increasing age (Pike et al., 2007). In the context of a structured 5-phase development framework, amyloid PET using aforementioned tracers has already reached the clinical utility phase (Cotta Ramusino et al., 2021). It has been established as a pathological biomarker for early and differential diagnosis of $\mathrm{AD}$ continuum based on both the international working group and the National Institute on Aging-Alzheimer's Association research AT(N) framework (Frisoni et al., 2017; Jack et al., 2018; Dubois et al., 2021) and recently proposed ATX $(\mathrm{N})$ conceptual framework (Hampel et al., 2021). To further ensure a standardized outcome measure, 
TABLE 1 | Positron emission tomography and SPECT imaging tracers for detecting proteinopathies; in vivo evaluation in human and in animal models.

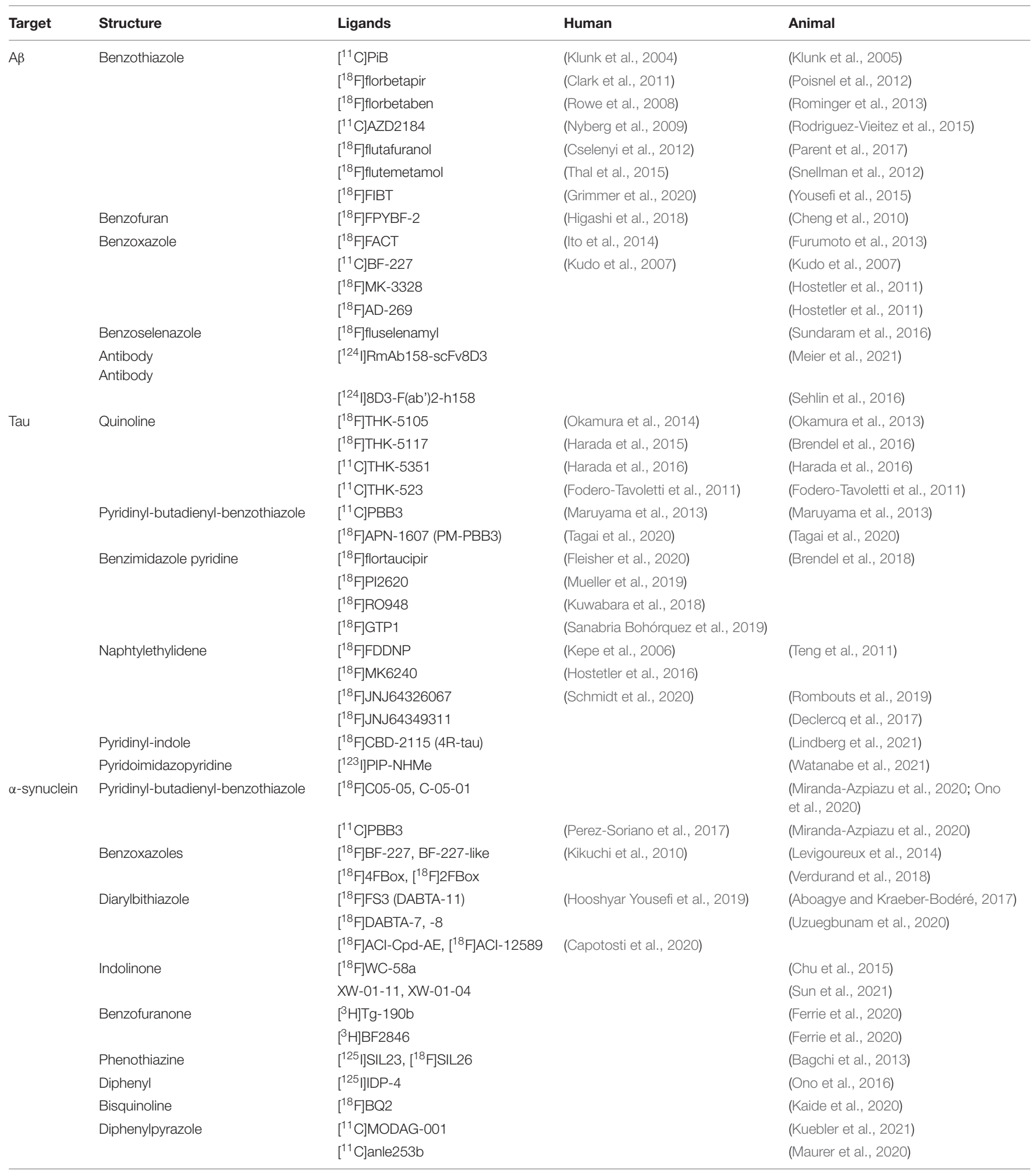

and to reduce the disagreement across amyloid-PET imaging, the readouts have been converted into Centiloid units (Klunk et al., 2015). This is based on the normalization of the data from $\left[{ }^{18} \mathrm{~F}\right]$ amyloid tracers relative to $\left[{ }^{11} \mathrm{C}\right] \mathrm{PiB}$, with young controls as zero and averages from typical patients with mild-moderate $\mathrm{AD}$ as 100 (Klunk et al., 2015). Recent probes with an improved 
binding specificity and lower bone uptake, such as $\left[{ }^{18} \mathrm{~F}\right] \mathrm{FIBT}$, $\left[{ }^{18} \mathrm{~F}\right] \mathrm{FACT}$, and $\left[{ }^{18} \mathrm{~F}\right] \mathrm{D} 15 \mathrm{FSP}$ (Ito et al., 2014; Grimmer et al., 2020; Xiao et al., 2021), or that detect diffuse amyloid, such as benzoselenazole derivative $\left[{ }^{18} \mathrm{~F}\right]$ fluselenamyl, have been developed (Sundaram et al., 2016). Antibody-based PET/singlephoton emission computed tomography (SPECT) tracers $\left[{ }^{124} \mathrm{I}\right] \mathrm{RmAb} 158-\mathrm{scFv} 8 \mathrm{D} 3$ and $\left[{ }^{124} \mathrm{I}\right] 8 \mathrm{D} 3-\mathrm{F}(\mathrm{ab}) 2$-h158 have showed sufficient blood-brain barrier entrance, by conjugating to transferrin receptor antibodies, in several transgenic mouse models of amyloidosis (Sehlin et al., 2016; Meier et al., 2021).

\section{Tau Imaging}

Microtubule-associated tau protein (MAPT) is located inside the neurons and is produced by alternative splicing from MAPT gene on chromosome 17. Tau has important physiological functions in regulating the axonal transport and neurite outgrowth and maintaining the microtubule stability (Chang et al., 2021). In $\mathrm{AD}$ brain, both 3-repeat (3R) and 4-repeat (4R) tau are presented, as $4 \mathrm{R}$ tau in CBD and PSP brain and $3 \mathrm{R}$ tau in Pick's disease brain (Iqbal et al., 2010; Shi et al., 2021b). Tau is abnormally hyperphosphorylated forming oligomer, fibrils, and NFTs (Iqbal et al., 2010; Spillantini and Goedert, 2013). In the $\mathrm{AD}$ brain, tangles accumulate first in the entorhinal cortex (Braak and Braak, 1991) and, subsequently, spread from the entorhinal cortex to the hippocampus and neocortex via neuronal projection, leading to the disruption of the microtubule stability and cell death (Holmes et al., 2014; Franzmeier et al., 2019). MRI readouts of neurodegeneration and functional network alterations associate with tau and $\mathrm{A} \beta$ accumulation detected by PET in patients with mild cognitive impairment and AD (Jacobs et al., 2018; Franzmeier et al., 2019; La Joie et al., 2020; Vogel et al., 2020). Several tau tracers have been developed, including first-generation $\left[{ }^{18} \mathrm{~F}\right]$ flortaucipir (Johnson et al., 2016), $\left[{ }^{11} \mathrm{C}\right]$ PBB3 (Maruyama et al., 2013), $\left[{ }^{11} \mathrm{C}\right] \mathrm{THK}-523$ (Fodero-Tavoletti et al., 2011), $\left[{ }^{18} \mathrm{~F}\right] \mathrm{THK}-5117$ (Okamura et al., 2013), $\left[{ }^{18} \mathrm{~F}\right]$ THK-5105 (Okamura et al., 2014), and $\left[{ }^{18} \mathrm{~F}\right] \mathrm{THK}-$ 5351 (Harada et al., 2016) and second-generation $\left[{ }^{18} \mathrm{~F}\right] \mathrm{MK} 6240$ (Lohith et al., 2019), $\left.{ }^{18} \mathrm{~F}\right]$ RO948 (Leuzy et al., 2020), $\left[{ }^{18} \mathrm{~F}\right] \mathrm{PI} 2620$ (Mueller et al., 2019), $\left[{ }^{18} \mathrm{~F}\right] \mathrm{PM}-\mathrm{PBB} 3$ (APN-1607) (Tagai et al., 2020), $\left[{ }^{18} \mathrm{~F}\right] J N J-64326067$ (Schmidt et al., 2020), and $\left[{ }^{18} \mathrm{~F}\right]$ GTP1 (Sanabria Bohórquez et al., 2019). In the context of a structured 5-phase development framework of biomarkers for AD, the firstand second-generation tau PET tracers are currently considered at the clinical validity phase (Bischof et al., 2021; Chiotis et al., 2021; Wolters et al., 2021). Among these tracers, $\left[{ }^{18} \mathrm{~F}\right]$ flortaucipir (Tauvid) has been approved by FDA for imaging tauopathy in patients with cognitive impairments undergoing evaluation for AD. $\left[{ }^{18} \mathrm{~F}\right]$ flortaucipir has been used in clinical trials to monitor the development of regional tauopathy in patients with $\mathrm{AD}$ during immunotherapy, targeting $\mathrm{A} \beta$ (Cummings et al., 2021a; Knopman et al., 2021). The off-target binding to monoamine oxidase-B (MAO-B) and in the choroid plexus was reported with the first-generation tracers, namely, $\left[{ }^{18} \mathrm{~F}\right]$ flortaucipir, $\left[{ }^{18} \mathrm{~F}\right] \mathrm{THK}$ 5117, and (S)- $\left[{ }^{18} \mathrm{~F}\right]$ THK-5117 (Sander et al., 2016; Lemoine et al., 2018; Wren et al., 2018; Murugan et al., 2019). In addition, Hansen et al. showed a decrease in the $\left[{ }^{18} \mathrm{~F}\right]$ flortaucipir binding to neuromelanin in the midbrain of patients with PD compared with controls, reflecting the loss of pigmented neurons in the substantial nigra (Hansen et al., 2016). With the improved design, no clear off-target binding was reported for the secondgeneration tau imaging probe in the choroid plexus in vivo (Mueller et al., 2019; Sanabria Bohórquez et al., 2019; Leuzy et al., 2020; Pascoal et al., 2020; Schmidt et al., 2020; Tagai et al., 2020) or to MAO-B in postmortem investigations (Yap et al., 2021). Leuzy et al. (2021) reported a multicenter comparison study and suggested that a common temporal lobe region of interest and cut-off can be used for the differential diagnosis of patients with dementia with $\left[{ }^{18} \mathrm{~F}\right]$ flortaucipir, $\left[{ }^{18} \mathrm{~F}\right] \mathrm{RO} 948$, and $\left[{ }^{18} \mathrm{~F}\right] \mathrm{MK} 6240$ tau PET (Figures 1A-C). For the primary tauopathy diseases, Kroth et al. (2019) and Brendel et al. (2020) showed that $\left[{ }^{18} \mathrm{~F}\right] \mathrm{PI} 2620$ showed a higher uptake in the basal ganglia of patients with PSP compared with that in controls by PET, with a high specificity in the brain from patients with PSP at the postmortem. Tagai et al. (2020) showed a distinct tau distribution pattern using PET with $\left[{ }^{18} \mathrm{~F}\right] \mathrm{PM}-\mathrm{PBB} 3$ in patients with PSP in the basal ganglia and patients with $\mathrm{AD}$ in the cortex and hippocampus compared with that in control. Yap et al. (2021) recently compared the second-generation probes PI2620, RO948, MK6240, and JNJ-64326067 in postmortem brain tissues from patients with AD, PSP, CBD, and Pick's disease by using autoradiography and immunohistochemistry and demonstrated that these tracers could detect cortical paired-helical-filament tau and a lower binding to cortical inclusions of primary tauopathies.

There is currently a lack of tracers specific for $4 \mathrm{R}$ tau. Animal models, such as P301L and P301S, that recapitulate pathological features of $4 \mathrm{R}$ tauopathy have been developed with mutations in the MAPT gene, (Lewis et al., 2000; Gotz et al., 2001; SantaCruz et al., 2005; Spires et al., 2006), as well as hTau and knock in animal models (Saito et al., 2019; Hosokawa et al., 2021). The in vivo imaging of tau has been demonstrated in animal models using $\left[{ }^{18} \mathrm{~F}\right] \mathrm{APN}-1607,\left[{ }^{11} \mathrm{C}\right] \mathrm{PBB} 3,\left[{ }^{11} \mathrm{C}\right] \mathrm{mPBB},\left[{ }^{18} \mathrm{~F}\right] \mathrm{THK} 5117$, and $\left[{ }^{18} \mathrm{~F}\right] \mathrm{JNJ} 64349311$ (Maruyama et al., 2013; Brendel et al., 2016, 2018; Declercq et al., 2017; Ishikawa et al., 2018; Ni et al., 2018; Tagai et al., 2020; Vagenknecht et al., 2021), as well as SPECT using $\left[{ }^{123} \mathrm{I}\right]$ PIP-NHMe (Watanabe et al., 2021). It is noted that $\left[{ }^{18} \mathrm{~F}\right]$ flortaucipir did not detect tau in the rTg4510 (P301L) 4R-tau mouse model (Marquié et al., 2015; Ni et al., 2018). More recently, tracer pyridinyl-indole derivative $\left[{ }^{18} \mathrm{~F}\right] \mathrm{CBD}-2115$ has shown $4 \mathrm{R}$-specific detection and promising brain uptake in mouse, rat, as well as non-human primate (Lindberg et al., 2021).

\section{$\alpha$-Synuclein Imaging}

A highly desired, but so far unmet clinical need, is the in vivo visualization of the cerebral accumulation of $\alpha$-synuclein in individuals with $\alpha$-synucleinopathies, including patients with PD, DLB, and MSA (Poewe et al., 2017; Attems et al., 2021). The $\alpha$-synuclein inclusions are mainly located in the presynaptic neurons in PD and DLB, while in oligodendroglial cells in MSA. Dopamine transporter imaging using $\left[{ }^{18} \mathrm{~F}\right]$ DOPA PET or $\left[{ }^{123} \mathrm{I}\right] \mathrm{FP}-\mathrm{CIT}$ SPECT (DAT scan) is commonly utilized to visualize dopaminergic deficits in PD (Maltais et al., 2020). $\left[{ }^{18} \mathrm{~F}\right] \mathrm{FDG}$ PET visualizes the cerebral glucose metabolism in DLB- and MSA-related patterns 


\section{A}
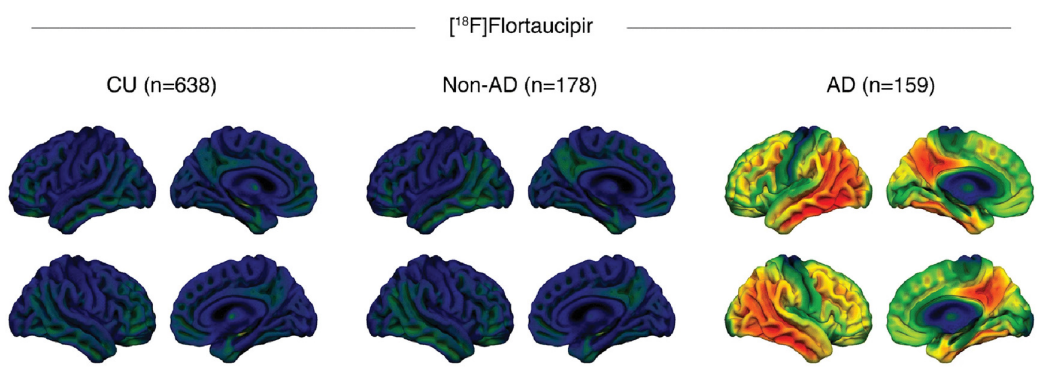

$0.5 \square$ SUVR 2.5

$\left[{ }^{18} \mathrm{~F}\right] \mathrm{RO} 048$

B

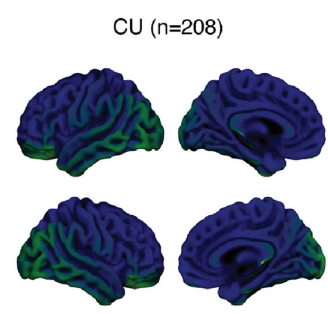

Non-AD ( $n=143)$
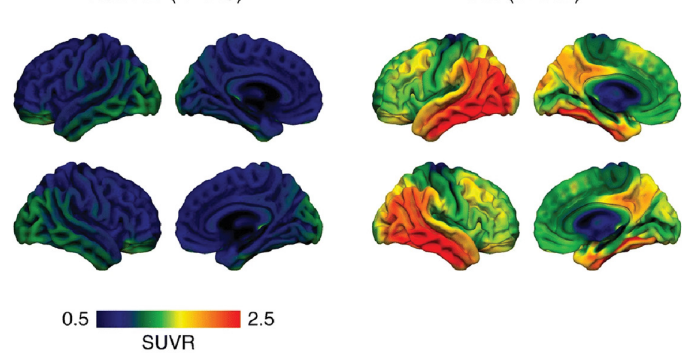

C

$\left[{ }^{18} \mathrm{~F}\right] \mathrm{MK} 6240$

$\mathrm{CU}(\mathrm{n}=218)$
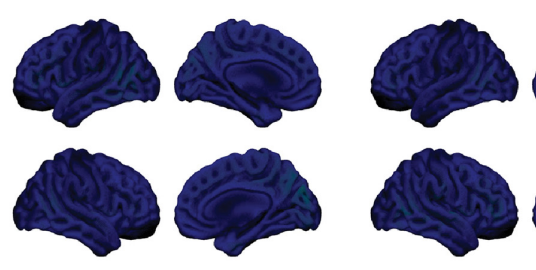

E

D

Paired helical filaments

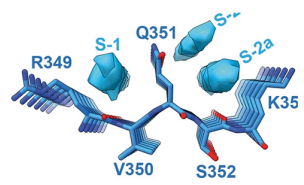

$0.5 \square 3.5$

Non-AD $(n=19)$
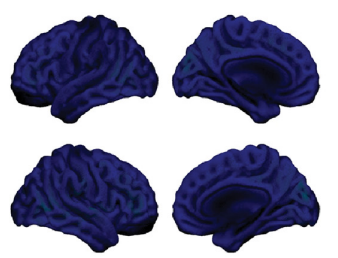

SUVR

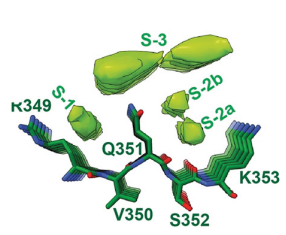

Straight filaments

F
$\operatorname{AD}(n=50)$
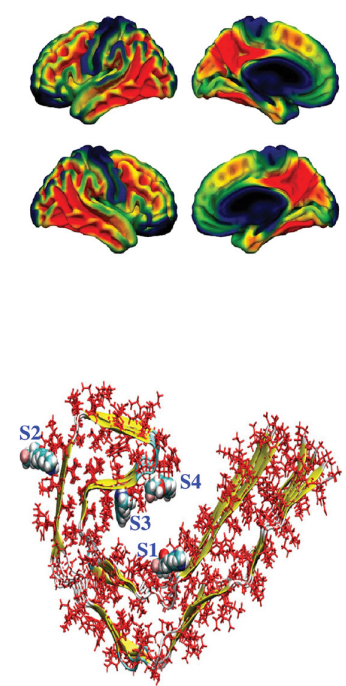

FIGURE 1 | In vivo and postmortem comparison of tau imaging probes in the human brain (A-C) multicenter comparison of positron emission tomography (PET) imaging using [ [ ${ }^{18} \mathrm{~F}$ flortaucipir, $\left[{ }^{18} \mathrm{~F}\right] \mathrm{RO} 948$, and [ $\left.{ }^{18} \mathrm{~F}\right] \mathrm{MK} 6240$, standardized uptake value ratios (SUVRs) across all participants within diagnostic groups; non-demented controls (CU), Alzheimer's disease (AD); reproduced from Leuzy et al. (2021) with permission from Springer Nature; (D,E) binding of APN-1607 (PM-PBB3) to tau-paired helical filaments and straight filaments is based on cryo-EM, top views and side views of the extra densities in the PM-PBB3 binding sites of paired helical filaments (D) and straight filaments (E) maps. The models of PM-PBB3 are shown near these extra densities at the same scale. Reproduced from Shi et al. (2021a) with permission from Springer Nature; and (F) various high-affinity binding sites of tau protofibril. The sites 1, 3 , and 4 are termed core sites as they are buried inside the fibril, whereas site 2 is termed a surface site as it is exposed to a greater amount of solvent molecules. Reproduced from Murugan et al. (2018) with permission from American Chemical Society.

(Niethammer and Eidelberg, 2012) and differentiates between patients with classical PD, atypical parkinsonian syndromes, and healthy control. The accumulation of misfolded $\alpha$ synuclein occurs at Braak stage 1 in $\mathrm{PD}$, preceding the loss of dopaminergic neurons that occurs at Braak stage 4 in the substantia nigra (Politis, 2014). Thus, the development of PET imaging for $\alpha$-synuclein deposits would enable an early diagnosis of $\alpha$-synucleinopathies and facilitate clinical trials targeting 

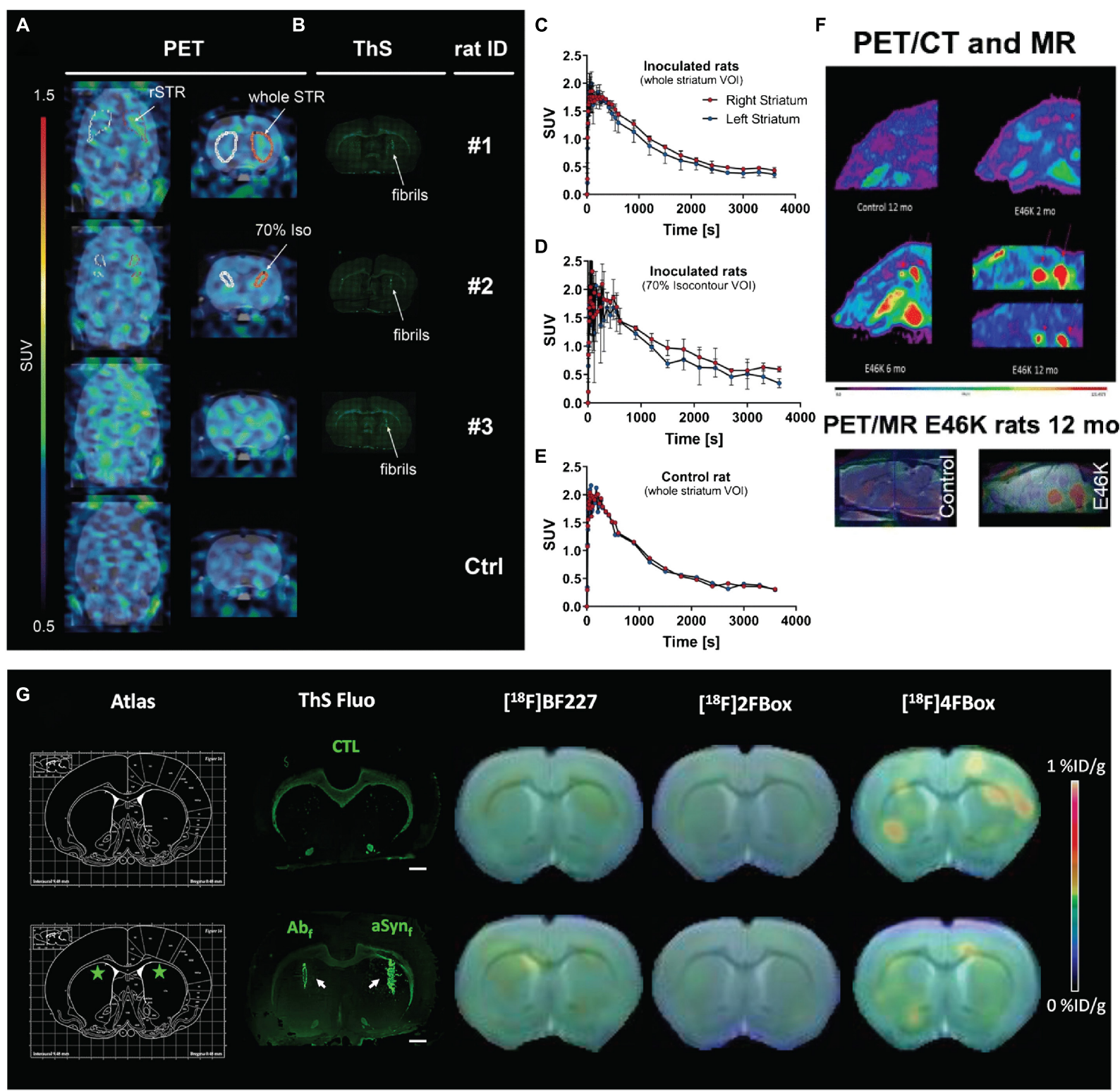

H

$\left[{ }^{18} \mathrm{~F}\right] \mathrm{BF} 227$

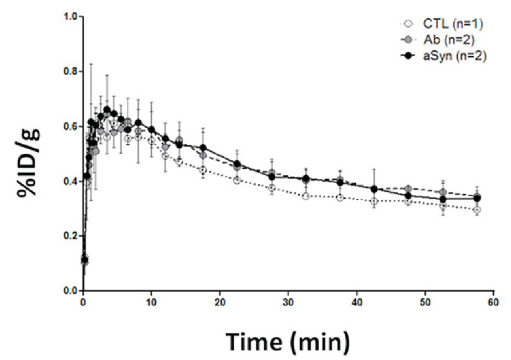

$\left[{ }^{18} \mathrm{~F}\right] 2 \mathrm{FBox}$

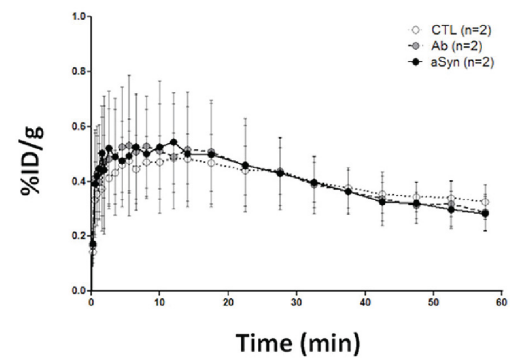

$\left[{ }^{18} \mathrm{~F}\right] 4 \mathrm{FBox}$

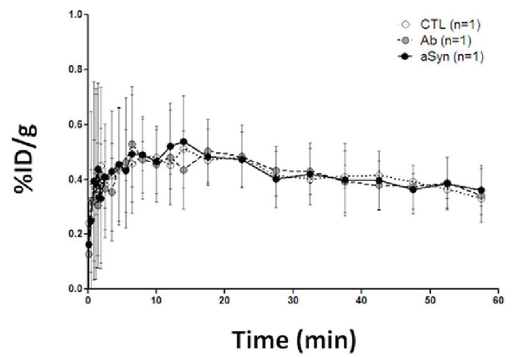

FIGURE 2 | In vivo $\alpha$-synuclein imaging in animal models. (A-E) In vivo binding of $\left(\mathrm{d}_{3}\right)-\left[{ }^{11} \mathrm{C}\right] \mathrm{MODAG}-001$ in $\alpha$-synuclein-inoculated rats. Coronal and transversal PET images (2.5-60 min) (A). Images show increased tracer accumulation in the $\alpha$-synuclein fibril-inoculated right striatum compared with the vehicle-injected contralateral striatum. Thioflavin-S staining (B) indicated $\alpha$-synuclein fibrils in the right striatum of fibril-inoculated rats (B). (C-E) Time activity curves of $\left(d_{3}\right)-\left[{ }^{11} \mathrm{C}\right]$ MODAG-001 higher signal in the right ( $\alpha$-synuclein injected) than left (vehicle injected) striatum; $\alpha$-SYN, $\alpha$-synuclein; rSTR, right striatum; ThS, thioflavin S; Ctrl, control; SUV, standardized uptake value, DVR-1, distribution volume ratio-1; VOI, voxel of interest; Reproduced from Kuebler et al. (2021) with permission from 
FIGURE 2 | Springer Nature. (F) $\left[{ }^{18}\right.$ F]DABTA-11 PET images in E46K rats show accumulation of the tracer in the medulla oblongata. The accumulation is apparent even at 2 months of age and is more prominent at 6 and 12 months of age with detectable uptake in the substantia nigra. PET/MRI and rat brain atlas confirm the regional uptake of the tracer. Reproduced from Yousefi et al. (2016) and Aboagye and Kraeber-Bodéré (2017) with permission from Springer Nature. (G,H) small-animal PET imaging with $\left[{ }^{18} \mathrm{~F}\right] \mathrm{BF} 227,\left[{ }^{18} \mathrm{~F}\right] 2 \mathrm{FB}$ ox , and $\left[{ }^{18} \mathrm{~F}\right] 4 \mathrm{FB}$ ox in control and fibril-injected rats. (G) Summed PET images were coregistered with CT images, and the radioactivity index was reflected by a color scale representing \%ID/g. ThS fluorescence staining of A 42 and $\alpha$-syn fibrils injected in the striata is presented (white arrows), with the corresponding stereotaxic brain atlas region (green stars representing injection sites). Scale bar represents $1 \mathrm{~mm}$ on ThS fluorescence staining. (H) Time activity curves (expressed in \% ID/g over time) for each radiotracer are presented. Values (mean \pm SD) were extracted from the striata regions based on an in-house-made MRI atlas that was coregistered to PET-CT images. Reproduced from Verdurand et al. (2018) with permission from American Chemical Society.

$\alpha$-synuclein (Poewe et al., 2017; Attems et al., 2021). A few structures and imaging tracers for $\alpha$-synuclein, such as BF-227 alike compounds, $\left[{ }^{11} \mathrm{C}\right] \mathrm{PBB} 3,\left[{ }^{18} \mathrm{~F}\right] \mathrm{C} 05-05,\left[{ }^{11} \mathrm{C}\right] \mathrm{MODAG}-001$, $\left[{ }^{18} \mathrm{~F}\right] \mathrm{FS} 3$ (or DABTA-11, $7,-8$ ), $\left[{ }^{18} \mathrm{~F}\right] \mathrm{ACI}-\mathrm{Cpd}-\mathrm{AE},\left[{ }^{18} \mathrm{~F}\right] \mathrm{ACI}-$ 12589, $\left[{ }^{18} \mathrm{~F}\right] 4 \mathrm{FBox}$, and $\left[{ }^{18} \mathrm{~F}\right] 2 \mathrm{FBox}$, have been identified and evaluated in vitro (Yu et al., 2012; Bagchi et al., 2013; Koga et al., 2017; Verdurand et al., 2018; Hooshyar Yousefi et al., 2019; Capotosti et al., 2020; Ono et al., 2020; Uzuegbunam et al., 2021; Table 1). Many of the current $\alpha$-synuclein PET tracers display insufficient selectivity, inadequate brain uptake, or pharmacokinetics. Among these, only four tracers have so far been evaluated in human subjects with $\alpha$-synucleinopathy, namely, (1) in vivo PET using $\left[{ }^{11} \mathrm{C}\right] \mathrm{BF}-227$ PET in patients with MSA showed higher brain accumulation compared with healthy control (Kikuchi et al., 2010). However, BF-227 also detects $A \beta$ pathology and is insensitive to $\alpha$-synuclein in brain from $\alpha$-synuclein transgenic mouse model (Levigoureux et al., 2014). (2) In vivo PET using $\left[{ }^{11} \mathrm{C}\right] \mathrm{PBB} 3$ has been performed in patients with MSA. However, the signal source was inconclusive due to the comorbidity in the brain (Perez-Soriano et al., 2017). $\left[{ }^{11} \mathrm{C}\right] \mathrm{PBB} 3$ showed a lower affinity and selectivity binding to $\alpha$-synuclein fibrils compared with tau fibrils in vitro. Given the nanomolar concentration of $\left[{ }^{11} \mathrm{C}\right] \mathrm{PBB} 3$ in in vivo PET, $\alpha$-synuclein pathology is likely below the detection threshold (Koga et al., 2017); (3) $\left[{ }^{18} \mathrm{~F}\right] \mathrm{FS} 3$ showed nanomolar affinity to $\alpha$-synuclein fibrils (around 100-folds selectivity over $\mathrm{A} \beta$ and tau fibrils), brain uptake in human, as well as in the medulla oblongata of E46K $\alpha$-synuclein rat model (Yousefi et al., 2016; Aboagye and Kraeber-Bodéré, 2017; Hooshyar Yousefi et al., 2019; Figure 2F); and (4) [ $\left.{ }^{18} \mathrm{~F}\right]$-ACI-Cpd-AE demonstrated a fast brain uptake, low non-specific binding, rapid metabolism, and $10 \%$ higher relative standard uptake value in the substantia nigra of patients with $\mathrm{PD}$ compared with those in healthy controls (Capotosti et al., 2020).

Several new $\alpha$-synuclein probes of different scaffolds have been reported recently with in vitro/in vivo evaluation in animal models. Verdurand et al. (2018) reported two new probes $\left[{ }^{18} \mathrm{~F}\right] 4 \mathrm{FBo}$ and $\left[{ }^{18} \mathrm{~F}\right] 2 \mathrm{FB}$ ox that bind to $\alpha$-synuclein and $A \beta$ fibrils that show sufficient brain uptake in a rat model but not in a mouse model with $\alpha$-synucleinopathy (Figures 2G,H). Kaide et al. (2020) developed a bisquinoline derivative $\left[{ }^{18} \mathrm{~F}\right] \mathrm{BQ} 2$ and showed a moderate brain uptake (i.e., $1.59 \% \mathrm{ID} / \mathrm{g}$ at $2 \mathrm{~min}$ and $1.35 \% \mathrm{ID} / \mathrm{g}$ at $60 \mathrm{~min}$ post injection) in the brain of a mouse model. Maurer et al. (2020) reported that diphenyl pyrazoles derivative $\left[{ }^{11} \mathrm{C}\right]$ anle253b, based on $\alpha$-synuclein oligomer modulator anle138b (Wagner et al., 2013; Wegrzynowicz et al., 2019), exhibited a good penetration in the blood-brain barrier, brain uptake, and low background binding to the non-pathological brain. Kuebler et al. (2021) reported that diphenyl pyrazole derivative $\left[{ }^{11} \mathrm{C}\right] \mathrm{MODAG}-001$ showed a high-affinity binding to $\alpha$-synuclein (i.e., $0.6 \mathrm{nM}, 30$-fold higher than to tau and $A \beta$ fibrils) and a sufficient brain uptake in $\alpha$-synuclein-inoculated rats (Figures 2A-E). Ono et al. recently reported that $\left[{ }^{18} \mathrm{~F}\right] \mathrm{C}-05-05$, a compound developed based on the PBB3 structure, showed specific detection of ps129 antibodypositive phosphorylated $\alpha$-synuclein in a mouse model, as well as in the non-human primate (Ono et al., 2020). In addition, several recent probes $\left[{ }^{18} \mathrm{~F}\right] \mathrm{WC}-58 \mathrm{a}$ (Chu et al., 2015), XW0104, XW01-64 (Sun et al., 2021), $\left[{ }^{3} \mathrm{H}\right] \mathrm{BF} 2846$, and $\left[{ }^{3} \mathrm{H}\right] \mathrm{Tg}-190 \mathrm{~b}$ (Ferrie et al., 2020) demonstrated $>30$-fold selectivity to $\alpha$ synuclein over $\mathrm{A} \beta$ (in silico and in vitro binding to fibrils) and in autoradiograph/staining in postmortem brain tissues.

\section{DISCUSSION}

The advances in PET detection of disease-specific pathological proteinopathy have facilitated the personalized and timely diagnosis of dementia and offers a window for therapeutic intervention (Hansson, 2021). The integration of PET imaging, assays of cerebrospinal fluid, MRI biomarkers, and forthcoming blood tests further increases the diagnostic power in early and differential diagnosis (Altomare et al., 2021; Cullen et al., 2021; Palmqvist et al., 2021). The application of new diseasemodifying treatment such as immunotherapy will likely require screening in prodromal patients for pathological evidence, e.g., cerebral $\mathrm{A} \beta$, tau, or $\alpha$-synuclein accumulation, and monitoring of treatment effects (Sevigny et al., 2016; Boxer et al., 2019; Rabinovici et al., 2019). In addition, proteinopathy imaging combined with PET for synaptic loss, mitochondria dysfunction, and neuroinflammation (e.g., astrocytosis and microgliosis) enables a more comprehensive understanding of the mechanism underlying neurodegeneration associated with proteinopathies (Calsolaro et al., 2021; Pascoal et al., 2021; Zhou R. et al., 2021).

Structural variations in $A \beta$ fibrils may contribute to variations in the disease onset and the progression rate of AD. The cryo-EM study has shown polymorphism of $\mathrm{A} \beta$ fibrils from the $\mathrm{AD}$ brain tissue (Kollmer et al., 2019). The in vivo imaging and postmortem studies have demonstrated different detection patterns of $\mathrm{A} \beta$ conformational variants in different autosomal-dominant AD (Schöll et al., 2012; Ni et al., 2017; Chen et al., 2021). In silico studies have implied six binding sites on $\mathrm{A} \beta$ fibrils, and amyloid tracers of different structures detect different sites on $A \beta$ fibrils or conformations (Murugan et al., 2016; Kuang et al., 2019). 
Tau molecular diversity and posttranslational modification are important contributors for the clinical heterogeneity in patients with AD (Dujardin et al., 2020). Four trajectories of diverse tau deposition pattern have been identified in the $\mathrm{AD}$ brain (Vogel et al., 2021). Shi et al. recently proposed a structurebased classification of tauopathy diseases underlined the tau strain heterogeneity and challenge in developing imaging probes specific for certain tau strain (Shi et al., 2021b). In vivo and postmortem comparative studies using different tau tracers indicated even more divergent patterns among tracers in primary tauopathies than in AD (Ono et al., 2017; Schonhaut et al., 2017; Chen et al., 2018; Endo et al., 2019; Ikeda et al., 2019; Leuzy et al., 2019; Arakhamia et al., 2020; Brendel et al., 2020; Tagai et al., 2020; Yap et al., 2021). Several recent in silico modeling studies suggest four binding sites on $\mathrm{AD}$ tau and highlighted the heterogeneity among probes binding to different tau strains: For the first-generation tracers, MK6240 and flortaucipir bind only to major binding site 1, while THK5351 binds to site 1 and 3, and PBB3 detects all four binding sites. For the second-generation tracers, PI2620, CBD-2115, and PM-PBB3 showed higher binding affinities to $\mathrm{CBD}$ tau compared with the $3 \mathrm{R} / 4 \mathrm{R}$ tracer MK6240, and CBD-2115 and PM-PBB3 demonstrated higher binding affinities to AD tau compared with PI2620 (Figure 1F; Murugan et al., 2018, 2021; Kuang et al., 2020; Zhou Y. et al., 2021). Recent study reported that PM-PBB3 showed similar binding sites in cryo-EM study toward tau filaments from $A D$, posterior cortical atrophy, and primary age-related tauopathy (Figures 1D,E; Fitzpatrick et al., 2017; Shi et al., 2021a). Further investigations are anticipated for elucidating the tracers binding with cryo-EM structures of tau filaments from CBD and PSP and for rational designing of disease (strain) specific to develop tracers with an increased specificity and binding activity (Fitzpatrick et al., 2017; Zhang et al., 2020). The challenges of $\alpha$-synuclein imaging stem from the intracellular location of $\alpha$ synuclein inclusions, distinct $\alpha$-synuclein strains, presence across different neurodegenerative diseases, and difficulty in finding a tracer with selectivity to $\alpha$-synuclein over $A \beta$ and tau fibrils (Yamasaki et al., 2019; Berg et al., 2021). Moreover, the cryo-EM structures of $\alpha$-synuclein filaments from the brains of patients with MSA differ from in vitro recombinant $\alpha$-synuclein fibrils

\section{REFERENCES}

Aboagye, E., and Kraeber-Bodéré, F. (2017). Highlights lecture EANM 2016: "Embracing molecular imaging and multi-modal imaging: a smart move for nuclear medicine towards personalized medicine”. Eur. J. Nucl. Med. Mol. Imaging 44, 1559-1574. doi: 10.1007/s00259-017-3704-6

Altmann, A., Ng, B., Landau, S., Jagust, W., and Greicius, M. (2015). Regional brain hypometabolism is unrelated to regional amyloid plaque burden. Brain 138, 3734-3746. doi: 10.1093/brain/awv278

Altomare, D., Caprioglio, C., Assal, F., Allali, G., Mendes, A., Ribaldi, F., et al. (2021). Diagnostic value of amyloid-PET and tau-PET: a head-to-head comparison. Eur. J. Nucl. Med. Mol. Imaging 48, 2200-2211. doi: 10.1007/ s00259-021-05246-x

Arakhamia, T., Lee, C. E., Carlomagno, Y., Duong, D. M., Kundinger, S. R., Wang, K., et al. (2020). Posttranslational modifications mediate the structural diversity of tauopathy strains. Cell 180, 633-644.e12. doi: 10.1016/j.cell.2020. 01.027

Araki, M., Matsumoto, S., Bekker, G.-J., Isaka, Y., Sagae, Y., Kamiya, N., et al. (2021). Exploring ligand binding pathways on proteins using
(Schweighauser et al., 2020). The different $\alpha$-synuclein strains contribute to the disease heterogeneity in animal models and in patients (Holec and Woerman, 2021). Klingstedt et al. (2019) and Shahnawaz et al. (2020) demonstrated a differential binding of a fluorescence luminescent-conjugated oligothiophenes probe to $\alpha$-synuclein fibrils derived from patients with MSA with that from patients with PD.

Further high-throughput screening and structure-activity relationship studies are needed to map the ligand binding site topology on $4 \mathrm{R}$-tau and $\alpha$-synuclein fibrils, to guide the development of tracers with a higher affinity and selectivity. In addition, deep learning-based drug development such as using AlphaFold or RoseTTaFold and on-chip pharmacokinetics may speed up the development and optimization of imaging tracers (Schneider, 2018; Bhhatarai et al., 2019; Baek et al., 2021; Jumper et al., 2021). Multiscale simulation pipeline combining methods with different accuracy/efficiency such as molecular docking, molecular dynamics simulation, and free energy calculation, will likely provide a high degree of validation of the simulations (Araki et al., 2021).

In summary, amyloid and tau PET imaging have a profound impact on the early and differential diagnosis of dementia and facilitated the development of disease-modifying therapeutics. Further development of $4 \mathrm{R}$ tau and $\alpha$-synuclein specific tracers is needed to fill the unmet need and move toward precision medicine in dementia.

\section{AUTHOR CONTRIBUTIONS}

$\mathrm{RN}$ wrote the draft manuscript. Both authors contributed to the manuscript.

\section{FUNDING}

$\mathrm{RN}$ received funding from Helmut Horten Stiftung, Jubiläumsstiftung von SwissLife, and Vontobel Stiftung, UZH Entrepreneur Fellowship of the University of Zurich, reference no. [MEDEF-20-021].

hypersound-accelerated molecular dynamics. Nat. Commun. 12:2793. doi: 10. 1038/s41467-021-23157-1

Attems, J., Toledo, J. B., Walker, L., Gelpi, E., Gentleman, S., Halliday, G., et al. (2021). Neuropathological consensus criteria for the evaluation of Lewy pathology in post-mortem brains: a multi-centre study. Acta Neuropathol. 141, 159-172. doi: 10.1007/s00401-020-02255-2

Baek, M., DiMaio, F., Anishchenko, I., Dauparas, J., Ovchinnikov, S., Lee, G. R., et al. (2021). Accurate prediction of protein structures and interactions using a three-track neural network. Science 373, 871-876. doi: 10.1126/science.abj8754

Bagchi, D. P., Yu, L., Perlmutter, J. S., Xu, J., Mach, R. H., Tu, Z., et al. (2013). Binding of the radioligand SIL23 to $\alpha$-synuclein fibrils in Parkinson disease brain tissue establishes feasibility and screening approaches for developing a Parkinson disease imaging agent. PLoS One 8:e55031. doi: 10.1371/journal. pone. 0055031

Bang, J., Spina, S., and Miller, B. L. (2015). Frontotemporal dementia. Lancet 386, 1672-1682.

Berg, D., Borghammer, P., Fereshtehnejad, S. M., Heinzel, S., Horsager, J., Schaeffer, E., et al. (2021). Prodromal Parkinson disease subtypes - key to understanding heterogeneity. Nat. Rev. Neurol. 17, 349-361. doi: 10.1038/s41582-021-00486-9 
Bhatt, J., Comas Herrera, A., Amico, F., Farina, N., Wong, J., Orange, J. B., et al. (2019). The World Alzheimer Report 2019: Attitudes to dementia.

Bhhatarai, B., Walters, W. P., Hop, C. E. C. A., Lanza, G., and Ekins, S. (2019). Opportunities and challenges using artificial intelligence in ADME/Tox. Nat. Mater. 18, 418-422. doi: 10.1038/s41563-019-0332-5

Bischof, G. N., Dodich, A., Boccardi, M., van Eimeren, T., Festari, C., Barthel, H., et al. (2021). Clinical validity of second-generation tau PET tracers as biomarkers for Alzheimer's disease in the context of a structured 5-phase development framework. Eur. J. Nucl. Med. Mol. Imaging 48, 2110-2120. doi: 10.1007/s00259-020-05156-4

Boxer, A. L., Qureshi, I., Ahlijanian, M., Grundman, M., Golbe, L. I., Litvan, I., et al. (2019). Safety of the tau-directed monoclonal antibody BIIB092 in progressive supranuclear palsy: a randomised, placebo-controlled, multiple ascending dose phase 1b trial. Lancet Neurol. 18, 549-558. doi: 10.1016/S1474-4422(19)30 $139-5$

Braak, H., and Braak, E. (1991). Neuropathological stageing of Alzheimer-related changes. Acta Neuropathol. 82, 239-259. doi: 10.1007/BF00308809

Brendel, M., Barthel, H., van Eimeren, T., Marek, K., Beyer, L., Song, M., et al. (2020). Assessment of 18F-PI-2620 as a biomarker in progressive supranuclear palsy. JAMA Neurol. 77, 1408-1419. doi: 10.1001/jamaneurol.2020.2526

Brendel, M., Jaworska, A., Probst, F., Overhoff, F., Korzhova, V., Lindner, S., et al. (2016). Small-animal PET imaging of tau pathology with 18F-THK5117 in 2 transgenic mouse models. J. Nucl. Med. 57, 792-798. doi: 10.2967/jnumed.115. 163493

Brendel, M., Yousefi, B. H., Blume, T., Herz, M., Focke, C., Deussing, M., et al. (2018). Comparison of 18F-T807 and 18F-THK5117 PET in a mouse model of tau pathology. Front. Aging Neurosci. 10:174. doi: 10.3389/fnagi.2018.00174

Calsolaro, V., Matthews, P. M., Donat, C. K., Livingston, N. R., Femminella, G. D., Guedes, S. S., et al. (2021). Astrocyte reactivity with late-onset cognitive impairment assessed in vivo using 11C-BU99008 PET and its relationship with amyloid load. Mol. Psychiatry doi: 10.1038/s41380-021-01193-z

Capotosti, F., Vokali, E., Molette, J., Tsika, E., Ravache, M., Juergens, T., et al. (2020). Developing a novel alpha-synuclein positron emission tomography (PET) tracer for the diagnosis of synucleinopathies. Alzheimers Dement. 16:e 043249 .

Chang, C.-W., Shao, E., and Mucke, L. (2021). Tau: enabler of diverse brain disorders and target of rapidly evolving therapeutic strategies. Science 371:eabb8255. doi: 10.1126/science.abb8255

Chen, C. D., Joseph-Mathurin, N., Sinha, N., Zhou, A., Li, Y., Friedrichsen, K., et al. (2021). Comparing amyloid- $\beta$ plaque burden with antemortem PiB PET in autosomal dominant and late-onset Alzheimer disease. Acta Neuropathol. 142, 689-706. doi: 10.1007/s00401-021-02342-y

Chen, J., Li, Y., Pirraglia, E., Okamura, N., Rusinek, H., and de Leon, M. J. (2018). Quantitative evaluation of tau PET tracers (18)F-THK5351 and (18)F-AV-1451 in Alzheimer's disease with standardized uptake value peak-alignment (SUVP) normalization. Eur. J. Nucl. Med. Mol. Imaging 45, 1596-1604. doi: 10.1007/ s00259-018-4040-1

Cheng, Y., Ono, M., Kimura, H., Kagawa, S., Nishii, R., and Saji, H. (2010). A novel ${ }^{18} \mathrm{~F}$-labeled pyridyl benzofuran derivative for imaging of $\beta$-amyloid plaques in Alzheimer's brains. Bioorg. Med. Chem. Lett. 20, 6141-6144. doi: 10.1016/j. bmcl.2010.08.016

Chételat, G., Arbizu, J., Barthel, H., Garibotto, V., Lammertsma, A. A., Law, I., et al. (2021). Finding our way through the labyrinth of dementia biomarkers. Eur. J. Nucl. Med. Mol. Imaging. 48, 2320-2324. doi: 10.1007/s00259-021-05301-7

Chételat, G., Arbizu, J., Barthel, H., Garibotto, V., Law, I., Morbelli, S., et al. (2020). Amyloid-PET and (18)F-FDG-PET in the diagnostic investigation of Alzheimer's disease and other dementias. Lancet Neurol. 19, 951-962. doi: 10. 1016/S1474-4422(20)30314-8

Chiotis, K., Dodich, A., Boccardi, M., Festari, C., Drzezga, A., Hansson, O., et al. (2021). Clinical validity of increased cortical binding of tau ligands of the THK family and PBB3 on PET as biomarkers for Alzheimer's disease in the context of a structured 5-phase development framework. Eur. J. Nucl. Med. Mol. Imaging 48, 2086-2096. doi: 10.1007/s00259-021-05277-4

Chu, W., Zhou, D., Gaba, V., Liu, J., Li, S., Peng, X., et al. (2015). Design, synthesis, and characterization of 3-(Benzylidene)indolin-2-one derivatives as ligands for $\alpha$-synuclein fibrils. J. Med. Chem. 58, 6002-6017. doi: 10.1021/acs.jmedchem. $5 b 00571$
Clark, C. M., Schneider, J. A., Bedell, B. J., Beach, T. G., Bilker, W. B., Mintun, M. A., et al. (2011). Use of florbetapir-PET for imaging beta-amyloid pathology. JAMA 305, 275-283. doi: 10.1001/jama.2010.2008

Cotta Ramusino, M., Perini, G., Altomare, D., Barbarino, P., Weidner, W., Salvini Porro, G., et al. (2021). Outcomes of clinical utility in amyloid-PET studies: state of art and future perspectives. Eur. J. Nucl. Med. Mol. Imaging 48, 2157-2168. doi: $10.1007 /$ s00259-020-05187-x

Crunkhorn, S. (2017). Antisense oligonucleotide reverses tau pathology. Nat. Rev. Drug Discov. 16, 166-166. doi: 10.1038/nrd.2017.37

Cselenyi, Z., Jonhagen, M. E., Forsberg, A., Halldin, C., Julin, P., Schou, M., et al. (2012). Clinical validation of 18F-AZD4694, an amyloid- $\beta$-specific PET radioligand. J. Nucl. Med. 53, 415-424. doi: 10.2967/jnumed.111.09 4029

Cullen, N. C., Leuzy, A., Janelidze, S., Palmqvist, S., Svenningsson, A. L., Stomrud, E., et al. (2021). Plasma biomarkers of Alzheimer's disease improve prediction of cognitive decline in cognitively unimpaired elderly populations. Nat. Commun. 12:3555. doi: 10.1038/s41467-021-23746-0

Cummings, J., Lee, G., Zhong, K., Fonseca, J., and Taghva, K. (2021b). Alzheimer's disease drug development pipeline: 2021. Alzheimers Dement (N Y) 7:e12179. doi: $10.1002 / \operatorname{trc} 2.12179$

Cummings, J., Aisen, P., Lemere, C., Atri, A., Sabbagh, M., and Salloway, S. (2021a). Aducanumab produced a clinically meaningful benefit in association with amyloid lowering. Alzheimers Res. Ther.13:98. doi: 10.1186/s13195-02100838-z

Curtis, C., Gamez, J. E., Singh, U., Sadowsky, C. H., Villena, T., Sabbagh, M. N., et al. (2015). Phase 3 trial of flutemetamol labeled with radioactive fluorine 18 imaging and neuritic plaque density. JAMA Neurol. 72, 287-294. doi: 10.1001/ jamaneurol.2014.4144

De Strooper, B., and Karran, E. (2016). The cellular phase of Alzheimer's disease. Cell 164, 603-615.

Declercq, L., Rombouts, F., Koole, M., Fierens, K., Mariën, J., Langlois, X., et al. (2017). Preclinical evaluation of 18F-JNJ64349311, a novel PET tracer for tau imaging. J. Nucl. Med. 58, 975-981. doi: 10.2967/jnumed.116.185199

Dubois, B., Villain, N., Frisoni, G. B., Rabinovici, G. D., Sabbagh, M., Cappa, S., et al. (2021). Clinical diagnosis of Alzheimer's disease: recommendations of the International Working Group. Lancet Neurol. 20, 484-496. doi: 10.1016/S14744422(21)00066- 1

Dujardin, S., Commins, C., Lathuiliere, A., Beerepoot, P., Fernandes, A. R., Kamath, T. V., et al. (2020). Tau molecular diversity contributes to clinical heterogeneity in Alzheimer's disease. Nat. Med. 26, 1256-1263.

Endo, H., Shimada, H., Sahara, N., Ono, M., Koga, S., Kitamura, S., et al. (2019). In vivo binding of a tau imaging probe, $[11 \mathrm{C}] \mathrm{PBB} 3$, in patients with progressive supranuclear palsy. Mov. Disord. 34, 744-754. doi: 10.1002/mds.27643

Fares, M. B., Jagannath, S., and Lashuel, H. A. (2021). Reverse engineering Lewy bodies: how far have we come and how far can we go? Nat. Rev. Neurosci. 22, 111-131. doi: 10.1038/s41583-020-00416-6

Ferrie, J. J., Lengyel-Zhand, Z., Janssen, B., Lougee, M. G., Giannakoulias, S., Hsieh, C.-J., et al. (2020). Identification of a nanomolar affinity $\alpha$-synuclein fibril imaging probe by ultra-high throughput in silico screening. Chem. Sci. 11, 12746-12754. doi: 10.1039/d0sc02159h

Fitzpatrick, A. W. P., Falcon, B., He, S., Murzin, A. G., Murshudov, G., Garringer, H. J., et al. (2017). Cryo-EM structures of tau filaments from Alzheimer's disease. Nature 547, 185-190.

Fleisher, A. S., Pontecorvo, M. J., Devous, M. D. Sr., Lu, M., Arora, A. K., Truocchio, S. P., et al. (2020). Positron emission tomography imaging with $\left[{ }^{18} \mathrm{~F}\right]$ flortaucipir and postmortem assessment of Alzheimer disease neuropathologic changes. JAMA Neurol. 77, 829-839. doi: 10.1001/jamaneurol.2020.0528

Fodero-Tavoletti, M. T., Okamura, N., Furumoto, S., Mulligan, R. S., Connor, A. R., McLean, C. A., et al. (2011). 18F-THK523: a novel in vivo tau imaging ligand for Alzheimer's disease. Brain 134, 1089-1100. doi: 10.1093/brain/awr038

Foster, N. L., Heidebrink, J. L., Clark, C. M., Jagust, W. J., Arnold, S. E., Barbas, N. R., et al. (2007). FDG-PET improves accuracy in distinguishing frontotemporal dementia and Alzheimer's disease. Brain 130, 2616-2635. doi: 10.1093/brain/awm177

Franzmeier, N., Rubinski, A., Neitzel, J., Kim, Y., Damm, A., Na, D. L., et al. (2019). Functional connectivity associated with tau levels in ageing, Alzheimer's, and small vessel disease. Brain 142, 1093-1107. doi: 10.1093/brain/awz026 
Frisoni, G. B., Boccardi, M., Barkhof, F., Blennow, K., Cappa, S., Chiotis, K., et al. (2017). Strategic roadmap for an early diagnosis of Alzheimer's disease based on biomarkers. Lancet Neurol. 16, 661-676. doi: 10.1016/S1474-4422(17) 30159-X

Furukawa, K., Okamura, N., Tashiro, M., Waragai, M., Furumoto, S., Iwata, R., et al. (2009). Amyloid PET in mild cognitive impairment and Alzheimer's disease with BF-227: comparison to FDG-PET. J. Neurol. 257, 721-727. doi: 10.1007/s00415-009-5396-8

Furumoto, S., Okamura, N., Furukawa, K., Tashiro, M., Ishikawa, Y., Sugi, K., et al. (2013). A ${ }^{18}$ F-labeled BF-227 derivative as a potential radioligand for imaging dense amyloid plaques by positron emission tomography. Mol. Imaging Biol. 15, 497-506. doi: 10.1007/s11307-012-0608-5

Goedert, M. (2015). Alzheimer's and Parkinson's diseases: the prion concept in relation to assembled $A \beta$, tau, and $\alpha$-synuclein. Science 349:1255555. doi: 10 . 1126/science. 1255555

Gotz, J., Chen, F., van Dorpe, J., and Nitsch, R. M. (2001). Formation of neurofibrillary tangles in P301l tau transgenic mice induced by Abeta 42 fibrils. Science 293, 1491-1495. doi: 10.1126/science.1062097

Grimmer, T., Shi, K., Diehl-Schmid, J., Natale, B., Drzezga, A., Förster, S., et al. (2020). (18)F-FIBT may expand PET for $\beta$-amyloid imaging in neurodegenerative diseases. Mol. Psychiatry 25, 2608-2619.

Haass, C., and Selkoe, D. J. (2007). Soluble protein oligomers in neurodegeneration: lessons from the Alzheimer's amyloid beta-peptide. Nat. Rev. Mol. Cell Biol. 8, 101-112. doi: 10.1038/nrm2101

Hampel, H., Cummings, J., Blennow, K., Gao, P., Jack, C. R. Jr., and Vergallo, A. (2021). Developing the ATX $(\mathrm{N})$ classification for use across the Alzheimer disease continuum. Nat. Rev. Neurol. 17, 580-589. doi: 10.1038/s41582-02100520-w

Hanseeuw, B. J., Betensky, R. A., Jacobs, H. I. L., Schultz, A. P., Sepulcre, J., Becker, J. A., et al. (2019). Association of amyloid and tau with cognition in preclinical Alzheimer disease: a longitudinal study. JAMA Neurol. 76, 915-924. doi: 10.1001/jamaneurol.2019.1424

Hansen, A. K., Knudsen, K., Lillethorup, T. P., Landau, A. M., Parbo, P., Fedorova, T., et al. (2016). In vivo imaging of neuromelanin in Parkinson's disease using 18 F-AV-1451 PET. Brain 139, 2039-2049. doi: 10.1093/brain/aww098

Hansson, O. (2021). Biomarkers for neurodegenerative diseases. Nat. Med. 27, 954-963. doi: 10.1093/jnen/nlaa041

Harada, R., Okamura, N., Furumoto, S., Furukawa, K., Ishiki, A., Tomita, N., et al. (2015). $\left[{ }^{18} \mathrm{~F}\right] \mathrm{THK}-5117$ PET for assessing neurofibrillary pathology in Alzheimer's disease. Eur. J. Nucl. Med. Mol. Imaging 42, 1052-1061. doi: 10. 1007/s00259-015-3035-4

Harada, R., Okamura, N., Furumoto, S., Furukawa, K., Ishiki, A., Tomita, N., et al. (2016). 18F-THK5351: a novel PET radiotracer for imaging neurofibrillary pathology in Alzheimer disease. J. Nucl. Med. 57, 208-214. doi: 10.2967/ jnumed.115.164848

Higashi, T., Nishii, R., Kagawa, S., Kishibe, Y., Takahashi, M., Okina, T., et al. (2018). ${ }^{18}$ F-FPYBF-2, a new F-18-labelled amyloid imaging PET tracer: first experience in 61 volunteers and 55 patients with dementia. Ann. Nucl. Med. 32, 206-216. doi: 10.1007/s12149-018-1236-1

Holec, S. A. M., and Woerman, A. L. (2021). Evidence of distinct $\alpha$-synuclein strains underlying disease heterogeneity. Acta Neuropathol. 142, 73-86. doi: 10.1007/s00401-020-02163-5

Holmes, B. B., Furman, J. L., Mahan, T. E., Yamasaki, T. R., Mirbaha, H., Eades, W. C., et al. (2014). Proteopathic tau seeding predicts tauopathy in vivo. Proc. Natl. Acad. Sci. U. S. A. 111, E4376-E4385. doi: 10.1073/pnas.1411649111

Hooshyar Yousefi, B., Shi, K., Arzberger, T., Wester, H. J., Schwaiger, M., Yakushev, I., et al. (2019). Translational study of a novel alpha-synuclein PET tracer designed for first-in-human investigating. Nuklearmedizin 58, L25.

Hosokawa, M., Masuda-Suzukake, M., Shitara, H., Shimozawa, A., Suzuki, G., Kondo, H., et al. (2021). Development of a novel tau propagation mouse model endogenously expressing 3 and 4 repeat tau isoforms. Brain doi: 10.1093/brain/ awab289

Hostetler, E. D., Sanabria-Bohórquez, S., Fan, H., Zeng, Z., Gammage, L., Miller, P., et al. (2011). [18F]Fluoroazabenzoxazoles as potential amyloid plaque PET tracers: synthesis and in vivo evaluation in rhesus monkey. Nucl. Med. Biol. 38, 1193-1203.

Hostetler, E. D., Walji, A. M., Zeng, Z., Miller, P., Bennacef, I., Salinas, C., et al. (2016). Preclinical characterization of ${ }^{18} \mathrm{~F}-\mathrm{MK}-6240$, a promising PET tracer for in vivo quantification of human neurofibrillary tangles. J. Nucl. Med. 57, 1599-1606. doi: 10.2967/jnumed.115.171678

Ikeda, A., Shimada, H., Nishioka, K., Takanashi, M., Hayashida, A., Li, Y., et al. (2019). Clinical heterogeneity of frontotemporal dementia and Parkinsonism linked to chromosome 17 caused by MAPT N279K mutation in relation to tau positron emission tomography features. Mov. Disord. 34, 568-574. doi: $10.1002 / \mathrm{mds} .27623$

Ikonomovic, M. D., Buckley, C. J., Abrahamson, E. E., Kofler, J. K., Mathis, C. A., Klunk, W. E., et al. (2020). Post-mortem analyses of PiB and flutemetamol in diffuse and cored amyloid- $\beta$ plaques in Alzheimer's disease. Acta Neuropathol. 140, 463-476. doi: 10.1007/s00401-020-02175-1

Iqbal, K., Liu, F., Gong, C. X., and Grundke-Iqbal, I. (2010). Tau in Alzheimer disease and related tauopathies. Curr. Alzheimer. Res. 7, 656-664. doi: 10.2174/ 156720510793611592

Irwin, D. J., Lee, V. M. Y., and Trojanowski, J. Q. (2013). Parkinson's disease dementia: convergence of $\alpha$-synuclein, tau and amyloid- $\beta$ pathologies. Nat. Rev. Neurosci. 14, 626-636. doi: 10.1038/nrn3549

Ishikawa, A., Tokunaga, M., Maeda, J., Minamihisamatsu, T., Shimojo, M., Takuwa, H., et al. (2018). In vivo visualization of tau accumulation, microglial activation, and brain atrophy in a mouse model of tauopathy rTg4510. J. Alzheimers Dis. 61, 1037-1052. doi: 10.3233/JAD-170509

Ito, H., Shinotoh, H., Shimada, H., Miyoshi, M., Yanai, K., Okamura, N., et al. (2014). Imaging of amyloid deposition in human brain using positron emission tomography and [18F]FACT: comparison with [11C]PIB. Eur. J. Nucl. Med. Mol. Imaging 41, 745-754. doi: 10.1007/s00259-013-2620-7

Jack, C. R. Jr., Bennett, D. A., Blennow, K., Carrillo, M. C., Dunn, B., Haeberlein, S. B., et al. (2018). NIA-AA Research Framework: toward a biological definition of Alzheimer's disease. Alzheimers Dement. 14, 535-562. doi: 10.1016/j.jalz. 2018.02.018

Jacobs, H. I. L., Hedden, T., Schultz, A. P., Sepulcre, J., Perea, R. D., Amariglio, R. E., et al. (2018). Structural tract alterations predict downstream tau accumulation in amyloid-positive older individuals. Nat. Neurosci. 21, 424-431. doi: 10.1038/ s41593-018-0070-z

Johnson, K. A., Schultz, A., Betensky, R. A., Becker, J. A., Sepulcre, J., Rentz, D., et al. (2016). Tau positron emission tomographic imaging in aging and early Alzheimer disease. Ann. Neurol. 79, 110-119. doi: 10.1002/ana.24546

Jucker, M., and Walker, L. C. (2018). Propagation and spread of pathogenic protein assemblies in neurodegenerative diseases. Nat. Neurosci. 21, 1341-1349. doi: 10.1038/s41593-018-0238-6

Jumper, J., Evans, R., Pritzel, A., Green, T., Figurnov, M., Ronneberger, O., et al. (2021). Highly accurate protein structure prediction with AlphaFold. Nature 596, 583-589. doi: 10.1038/s41586-021-03819-2

Kaide, S., Watanabe, H., Shimizu, Y., Iikuni, S., Nakamoto, Y., Hasegawa, M., et al. (2020). Identification and evaluation of bisquinoline scaffold as a new candidate for $\alpha$-synuclein-PET imaging. ACS Chem. Neurosci. 11, 4254-4261. doi: 10.1021/acschemneuro.0c00523

Kepe, V., Huang, S. C., Small, G. W., Satyamurthy, N., and Barrio, J. R. (2006). Visualizing pathology deposits in the living brain of patients with Alzheimer's disease. Methods Enzymol. 412, 144-160. doi: 10.1016/S0076-6879(06)12010-8

Kikuchi, A., Takeda, A., Okamura, N., Tashiro, M., Hasegawa, T., Furumoto, S., et al. (2010). In vivo visualization of alpha-synuclein deposition by carbon-11-labelled 2-[2-(2-dimethylaminothiazol-5-yl)ethenyl]-6-[2(fluoro)ethoxy]benzoxazole positron emission tomography in multiple system atrophy. Brain 133, 1772-1778. doi: 10.1093/brain/awq091

Klingstedt, T., Ghetti, B., Holton, J. L., Ling, H., Nilsson, K. P. R., and Goedert, M. (2019). Luminescent conjugated oligothiophenes distinguish between $\alpha$ synuclein assemblies of Parkinson's disease and multiple system atrophy. Acta Neuropathol. Commun. 7:193. doi: 10.1186/s40478-019-0840-1

Klunk, W. E., Engler, H., Nordberg, A., Wang, Y., Blomqvist, G., Holt, D. P., et al. (2004). Imaging brain amyloid in Alzheimer's disease with Pittsburgh Compound-B. Ann. Neurol. 55, 306-319. doi: 10.1002/ana.20009

Klunk, W. E., Koeppe, R. A., Price, J. C., Benzinger, T. L., Devous, M. D. Sr., Jagust, W. J., et al. (2015). The Centiloid Project: standardizing quantitative amyloid plaque estimation by PET. Alzheimers Dement. 11, 1-15.e1-4. doi: 10.1016/j.jalz.2014.07.003

Klunk, W. E., Lopresti, B. J., Ikonomovic, M. D., Lefterov, I. M., Koldamova, R. P., Abrahamson, E. E., et al. (2005). Binding of the positron emission tomography tracer Pittsburgh compound-B reflects the amount of amyloid-beta 
in Alzheimer's disease brain but not in transgenic mouse brain. J. Neurosci. 25, 10598-10606. doi: 10.1523/JNEUROSCI.2990-05.2005

Knopman, D. S., Amieva, H., Petersen, R. C., Chételat, G., Holtzman, D. M., Hyman, B. T., et al. (2021). Alzheimer disease. Nat. Rev. Dis. Primers. $7: 33$.

Koga, S., Ono, M., Sahara, N., Higuchi, M., and Dickson, D. W. (2017). Fluorescence and autoradiographic evaluation of tau PET ligand PBB3 to $\alpha$-synuclein pathology. Mov. Disord. 32, 884-892. doi: 10.1002/mds.27013

Kollmer, M., Close, W., Funk, L., Rasmussen, J., Bsoul, A., Schierhorn, A., et al. (2019). Cryo-EM structure and polymorphism of $A \beta$ amyloid fibrils purified from Alzheimer's brain tissue. Nat. Commun. 10:4760. doi: 10.1038/s41467019-12683-8

Kroth, H., Oden, F., Molette, J., Schieferstein, H., Capotosti, F., Mueller, A., et al. (2019). Discovery and preclinical characterization of [(18)F]PI-2620, a nextgeneration tau PET tracer for the assessment of tau pathology in Alzheimer's disease and other tauopathies. Eur. J. Nucl. Med. Mol. Imaging 46, 2178-2189. doi: 10.1007/s00259-019-04397-2

Kuang, G., Murugan, N. A., and Ågren, H. (2019). Mechanistic Insight into the Binding Profile of DCVJ and $\alpha$-synuclein fibril revealed by multiscale simulations. ACS Chem. Neurosci. 10, 610-617. doi: 10.1021/acschemneuro. $8 \mathrm{~b} 00465$

Kuang, G., Murugan, N. A., Zhou, Y., Nordberg, A., and Ågren, H. (2020). Computational insight into the binding profile of the Second-Generation PET tracer PI2620 with tau fibrils. ACS Chem. Neurosci. 11, 900-908. doi: 10.1021/ acschemneuro.9b00578

Kudo, Y., Okamura, N., Furumoto, S., Tashiro, M., Furukawa, K., Maruyama, M., et al. (2007). 2-(2-[2-Dimethylaminothiazol-5-yl]ethenyl)-6- (2[fluoro] ethoxy)benzoxazole: a novel PET agent for in vivo detection of dense amyloid plaques in Alzheimer's disease patients. J. Nucl. Med. 48, 553-561. doi: 10.2967/jnumed.106.037556

Kuebler, L., Buss, S., Leonov, A., Ryazanov, S., Schmidt, F., Maurer, A., et al. (2021). [(11)C]MODAG-001-towards a PET tracer targeting $\alpha$-synuclein aggregates. Eur. J. Nucl. Med. Mol. Imaging 48, 1759-1772.

Kuwabara, H., Comley, R. A., Borroni, E., Honer, M., Kitmiller, K., Roberts, J., et al. (2018). Evaluation of ${ }^{18} \mathrm{~F}-\mathrm{RO}-948$ PET for quantitative assessment of tau accumulation in the human brain. J. Nucl. Med. 59, 1877-1884. doi: 10.2967/ jnumed.118.214437

La Joie, R., Visani, A. V., Baker, S. L., Brown, J. A., Bourakova, V., Cha, J., et al. (2020). Prospective longitudinal atrophy in Alzheimer's disease correlates with the intensity and topography of baseline tau-PET. Sci. Transl. Med. 12:eaau5732. doi: 10.1126/scitranslmed.aau5732

Lambert, M. P., Velasco, P. T., Chang, L., Viola, K. L., Fernandez, S., Lacor, P. N., et al. (2007). Monoclonal antibodies that target pathological assemblies of $A \beta$. J. Neurochem. 100, 23-35. doi: 10.1111/j.1471-4159.2006.04157.x

Lemoine, L., Leuzy, A., Chiotis, K., Rodriguez-Vieitez, E., and Nordberg, A. (2018). Tau positron emission tomography imaging in tauopathies: the added hurdle of off-target binding. Alzheimers Dement. (Amst.) 10, 232-236. doi: 10.1016/j. dadm.2018.01.007

Lesné, S., Koh, M. T., Kotilinek, L., Kayed, R., Glabe, C. G., Yang, A., et al. (2006). A specific amyloid- $\beta$ protein assembly in the brain impairs memory. Nature 440 , 352-357. doi: 10.1038/nature 04533

Leuzy, A., Chiotis, K., Lemoine, L., Gillberg, P. G., Almkvist, O., Rodriguez-Vieitez, E., et al. (2019). Tau PET imaging in neurodegenerative tauopathies-still a challenge. Mol. Psychiatry 24, 1112-1134. doi: 10.1038/s41380-018-0342-8

Leuzy, A., Pascoal, T. A., Strandberg, O., Insel, P., Smith, R., Mattsson-Carlgren, N., et al. (2021). A multicenter comparison of [(18)F]flortaucipir, [(18)F]RO948, and [(18)F]MK6240 tau PET tracers to detect a common target ROI for differential diagnosis. Eur. J. Nucl. Med. Mol. Imaging 48, 2295-2305. doi: 10.1007/s00259-021-05401-4

Leuzy, A., Smith, R., Ossenkoppele, R., Santillo, A., Borroni, E., Klein, G., et al. (2020). Diagnostic performance of RO948 F 18 tau positron emission tomography in the differentiation of Alzheimer disease from other neurodegenerative disorders. JAMA Neurol. 77, 955-965. doi: 10.1001/ jamaneurol.2020.0989

Levigoureux, E., Lancelot, S., Bouillot, C., Chauveau, F., Verdurand, M., Verchere, J., et al. (2014). Binding of the PET radiotracer $\left[{ }^{18} \mathrm{~F}\right] \mathrm{BF} 227$ does not reflect the presence of alpha-synuclein aggregates in transgenic mice. Curr. Alzheimer Res. $11,955-960$.
Lewis, J., McGowan, E., Rockwood, J., Melrose, H., Nacharaju, P., Van Slegtenhorst, M., et al. (2000). Neurofibrillary tangles, amyotrophy and progressive motor disturbance in mice expressing mutant (P301L) tau protein. Nat. Genet. 25, 402-405. doi: 10.1038/78078

Lindberg, A., Knight, A. C., Sohn, D., Rakos, L., Tong, J., Radelet, A., et al. (2021). Radiosynthesis, in vitro and in vivo evaluation of [(18)F]CBD-2115 as a first-in-class radiotracer for imaging $4 \mathrm{R}$-tauopathies. ACS Chem. Neurosci. 12, 596-602.

Lohith, T. G., Bennacef, I., Vandenberghe, R., Vandenbulcke, M., Salinas, C. A., Declercq, R., et al. (2019). Brain imaging of Alzheimer dementia patients and elderly controls with (18)F-MK-6240, a PET tracer targeting neurofibrillary tangles. J. Nucl. Med. 60, 107-114. doi: 10.2967/jnumed.118.208215

Maltais, D. D., Jordan, L. G., Min, H. K., Miyagawa, T., Przybelski, S. A., Lesnick, T. G., et al. (2020). Confirmation of (123)I-FP-CIT SPECT quantification methods in dementia with lewy bodies and other neurodegenerative disorders. J. Nucl. Med. 61, 1628-1635. doi: 10.2967/jnumed.119.239418

Marquié, M., Normandin, M. D., Vanderburg, C. R., Costantino, I. M., Bien, E. A., Rycyna, L. G., et al. (2015). Validating novel tau positron emission tomography tracer [F-18]-AV-1451 (T807) on postmortem brain tissue. Ann. Neurol. 78, 787-800. doi: 10.1002/ana.24517

Maruyama, M., Shimada, H., Suhara, T., Shinotoh, H., Ji, B., Maeda, J., et al. (2013). Imaging of tau pathology in a tauopathy mouse model and in Alzheimer patients compared to normal controls. Neuron 79, 1094-1108. doi: 10.1016/j. neuron.2013.07.037

Maurer, A., Leonov, A., Ryazanov, S., Herfert, K., Kuebler, L., Buss, S., et al. (2020). (11) C radiolabeling of anle253b: a putative PET tracer for Parkinson's disease that binds to $\alpha$-synuclein fibrils in vitro and crosses the blood-brain barrier. ChemMedChem 15, 411-415. doi: 10.1002/cmdc.201900689

Meier, S. R., Sehlin, D., Roshanbin, S., Lim Falk, V., Saito, T., Saido, T. C., et al. (2021). (11)C-PIB and (124)I-antibody PET provide differing estimates of brain amyloid-beta after therapeutic intervention. J. Nucl. Med. [Epub ahead of print]. doi: 10.2967/jnumed.121.262083

Miranda-Azpiazu, P., Svedberg, M., Higuchi, M., Ono, M., Jia, Z., Sunnemark, D., et al. (2020). Identification and in vitro characterization of C05-01, a PBB3 derivative with improved affinity for alpha-synuclein. Brain Res. 1749:147131. doi: 10.1016/j.brainres.2020.147131

Mueller, A., Bullich, S., Barret, O., Madonia, J., Berndt, M., Papin, C., et al. (2019). Tau PET imaging with (18)F-PI-2620 in patients with Alzheimer's disease and healthy controls: a first-in-human study. J. Nucl. Med. 61, 911-919. doi: 10. 2967/jnumed.119.236224

Murugan, N. A., Chiotis, K., Rodriguez-Vieitez, E., Lemoine, L., Agren, H., and Nordberg, A. (2019). Cross-interaction of tau PET tracers with monoamine oxidase B: evidence from in silico modelling and in vivo imaging. Eur. J. Nucl. Med. Mol. Imaging 46, 1369-1382. doi: 10.1007/s00259-019-04305-8

Murugan, N. A., Halldin, C., Nordberg, A., Långström, B., and Ågren, H. (2016). The culprit is in the cave: the core sites explain the binding profiles of amyloidspecific tracers. J. Phys. Chem. Lett. 7, 3313-3321. doi: 10.1021/acs.jpclett. $6 \mathrm{~b} 01586$

Murugan, N. A., Nordberg, A., and Ågren, H. (2018). Different positron emission tomography tau tracers bind to multiple binding sites on the tau fibril: insight from computational modeling. ACS Chem. Neurosci. 9, 1757-1767. doi: 10. 1021/acschemneuro. 8 b00093

Murugan, N. A., Nordberg, A., and Ågren, H. (2021). Cryptic sites in tau fibrils explain the preferential binding of the AV-1451 PET tracer toward Alzheimer's tauopathy. ACS Chem. Neurosci. 12, 2437-2447. doi: 10.1021/acschemneuro. 0c00340

Nelissen, N., Van Laere, K., Thurfjell, L., Owenius, R., Vandenbulcke, M., Koole, M., et al. (2009). Phase 1 study of the Pittsburgh compound B derivative $18 \mathrm{~F}$-flutemetamol in healthy volunteers and patients with probable Alzheimer disease. J. Nucl. Med. 50, 1251-1259. doi: 10.2967/jnumed.109.06 3305

Ni, R. (2021). Positron emission tomography in animal models of Alzheimer's disease amyloidosis: translational implications. Pharmaceuticals 14:1179. doi: 10.3390/ph14111179

Ni, R., Gillberg, P. G., Bogdanovic, N., Viitanen, M., Myllykangas, L., Nennesmo, I., et al. (2017). Amyloid tracers binding sites in autosomal dominant and sporadic Alzheimer's disease. Alzheimers Dement. 13, 419-430. doi: 10.1016/j.jalz.2016. 08.006 
Ni, R., Ji, B., Ono, M., Sahara, N., Zhang, M. R., Aoki, I., et al. (2018). Comparative in-vitro and in-vivo quantifications of pathological tau deposits and their association with neurodegeneration in tauopathy mouse models. J. Nucl. Med. 59, 960-966. doi: 10.2967/jnumed.117.201632

Ni, R., Röjdner, J., Voytenko, L., Dyrks, T., Thiele, A., Marutle, A., et al. (2021). In vitro characterization of the regional binding distribution of amyloid PET tracer florbetaben and the glia tracers deprenyl and PK1195 in autopsy Alzheimer's brain tissue. J. Alzheimers Dis. 80, 1723-1737. doi: 10.3233/JAD201344

Niethammer, M., and Eidelberg, D. (2012). Metabolic brain networks in translational neurology: concepts and applications. Ann. Neurol. 72, 635-647. doi: 10.1002/ana.23631

Nyberg, S., Jonhagen, M. E., Cselenyi, Z., Halldin, C., Julin, P., Olsson, H., et al. (2009). Detection of amyloid in Alzheimer's disease with positron emission tomography using [11C]AZD2184. Eur. J. Nucl. Med. Mol. Imaging 36, 18591863. doi: 10.1007/s00259-009-1182-1

Okamura, N., Furumoto, S., Fodero-Tavoletti, M. T., Mulligan, R. S., Harada, R., Yates, P., et al. (2014). Non-invasive assessment of Alzheimer's disease neurofibrillary pathology using 18F-THK5105 PET. Brain 137, 1762-1771. doi: 10.1093/brain/awu064

Okamura, N., Furumoto, S., Harada, R., Tago, T., Yoshikawa, T., Fodero-Tavoletti, M., et al. (2013). Novel 18F-labeled arylquinoline derivatives for noninvasive imaging of tau pathology in Alzheimer disease. J. Nucl. Med. 54, 1420-1427. doi: $10.2967 /$ jnumed.112.117341

Ono, M., Doi, Y., Watanabe, H., Ihara, M., Ozaki, A., and Saji, H. (2016). Structureactivity relationships of radioiodinated diphenyl derivatives with different conjugated double bonds as ligands for $\alpha$-synuclein aggregates. RSC Adv. 6, 44305-44312. doi: 10.1039/C6RA02710E

Ono, M., Sahara, N., Kumata, K., Ji, B., Ni, R., Koga, S., et al. (2017). Distinct binding of PET ligands PBB3 and AV-1451 to tau fibril strains in neurodegenerative tauopathies. Brain 140, 764-780. doi: 10.1093/brain/ aww339

Ono, M., Takahashi, M., Shimozawa, A., Fujinaga, M., Mori, W., Nagai, Y., et al. (2020). In vivo visualization of propagating $\alpha$-synuclein pathologies in mouse and marmoset models by a bimodal imaging probe. SocArXiv [Preprint]. doi: 10.1101/2020.10.23.349860.

Palmqvist, S., Schöll, M., Strandberg, O., Mattsson, N., Stomrud, E., Zetterberg, H., et al. (2017). Earliest accumulation of $\beta$-amyloid occurs within the default-mode network and concurrently affects brain connectivity. Nat. Commun. 8:1214. doi: 10.1038/s41467-017-01150-x

Palmqvist, S., Tideman, P., Cullen, N., Zetterberg, H., Blennow, K., Dage, J. L., et al. (2021). Prediction of future Alzheimer's disease dementia using plasma phospho-tau combined with other accessible measures. Nat. Med. 27, 10341042. doi: 10.1038/s41591-021-01348-z

Parent, M. J., Zimmer, E. R., Shin, M., Kang, M. S., Fonov, V. S., Mathieu, A., et al. (2017). Multimodal imaging in rat model recapitulates Alzheimer's disease biomarkers abnormalities. J. Neurosci. 37, 12263-12271. doi: 10.1523/ JNEUROSCI.1346-17.2017

Park, L., Hochrainer, K., Hattori, Y., Ahn, S. J., Anfray, A., Wang, G., et al. (2020). Tau induces PSD95-neuronal NOS uncoupling and neurovascular dysfunction independent of neurodegeneration. Nat. Neurosci. 23, 1079-1089. doi: 10.1038/ s41593-020-0686-7

Pascoal, T. A., Benedet, A. L., Ashton, N. J., Kang, M. S., Therriault, J., Chamoun, M., et al. (2021). Microglial activation and tau propagate jointly across Braak stages. Nat. Med. 27, 1592-1599. doi: 10.1038/s41591-021-01456-w

Pascoal, T. A., Therriault, J., Benedet, A. L., Savard, M., Lussier, F. Z., Chamoun, M., et al. (2020). 18F-MK-6240 PET for early and late detection of neurofibrillary tangles. Brain 143, 2818-2830. doi: 10.1093/brain/awaa180

Perez-Soriano, A., Arena, J. E., Dinelle, K., Miao, Q., McKenzie, J., Neilson, N., et al. (2017). PBB3 imaging in Parkinsonian disorders: evidence for binding to tau and other proteins. Mov. Disord. 32, 1016-1024. doi: 10.1002/mds.27029

Pievani, M., Filippini, N., van den Heuvel, M. P., Cappa, S. F., and Frisoni, G. B. (2014). Brain connectivity in neurodegenerative diseases-from phenotype to proteinopathy. Nat. Rev. Neurol. 10, 620-633. doi: 10.1038/nrneurol.2014.178

Pike, K. E., Savage, G., Villemagne, V. L., Ng, S., Moss, S. A., Maruff, P., et al. (2007). Beta-amyloid imaging and memory in non-demented individuals: evidence for preclinical Alzheimer's disease. Brain 130, 2837-2844. doi: 10.1093/brain/ awm 238
Pike, V. W. (2009). PET radiotracers: crossing the blood-brain barrier and surviving metabolism. Trends Pharmacol. Sci. 30, 431-440. doi: 10.1016/j.tips. 2009.05.005

Poewe, W., Seppi, K., Tanner, C. M., Halliday, G. M., Brundin, P., Volkmann, J., et al. (2017). Parkinson disease. Nat. Rev. Dis. Primers 3:17013.

Poisnel, G., Dhilly, M., Moustié, O., Delamare, J., Abbas, A., Guilloteau, D., et al. (2012). PET imaging with [18F]AV-45 in an APP/PS1-21 murine model of amyloid plaque deposition. Neurobiol. Aging 33, 2561-2571. doi: 10.1016/j. neurobiolaging.2011.12.024

Politis, M. (2014). Neuroimaging in Parkinson disease: from research setting to clinical practice. Nat. Rev. Neurol. 10, 708-722. doi: 10.1038/nrneurol. 2014.205

Rabinovici, G. D., Gatsonis, C., Apgar, C., Chaudhary, K., Gareen, I., Hanna, L., et al. (2019). Association of amyloid positron emission tomography with subsequent change in clinical management among medicare beneficiaries with mild cognitive impairment or dementia. JAMA 321, 1286-1294. doi: 10.1001/ jama.2019.2000

Rodriguez-Vieitez, E., Ni, R., Gulyas, B., Toth, M., Haggkvist, J., Halldin, C., et al. (2015). Astrocytosis precedes amyloid plaque deposition in Alzheimer APPswe transgenic mouse brain: a correlative positron emission tomography and in vitro imaging study. Eur. J. Nucl. Med. Mol. Imaging 42, 1119-1132. doi: 10.1007/s00259-015-3047-0

Rombouts, F. J. R., Declercq, L., Andrés, J. I., Bottelbergs, A., Chen, L., Iturrino, L., et al. (2019). Discovery of N-(4-[ $\left[{ }^{18} \mathrm{~F}\right]$ fluoro-5-methylpyridin-2-yl)isoquinolin6-amine (JNJ-64326067), a new promising tau positron emission tomography imaging tracer. J. Med. Chem. 62, 2974-2987. doi: 10.1021/acs.jmedchem. 8 b01759

Rominger, A., Brendel, M., Burgold, S., Keppler, K., Baumann, K., Xiong, G., et al. (2013). Longitudinal assessment of cerebral $\beta$-amyloid deposition in mice overexpressing Swedish mutant $\beta$-amyloid precursor protein using $18 \mathrm{~F}$ florbetaben PET. J. Nucl. Med. 54, 1127-1134. doi: 10.2967/jnumed.112.114660 Rowe, C. C., Ackerman, U., Browne, W., Mulligan, R., Pike, K. L., O’Keefe, G., et al. (2008). Imaging of amyloid beta in Alzheimer's disease with 18F-BAY949172, a novel PET tracer: proof of mechanism. Lancet Neurol. 7, 129-135. doi: 10.1016/S1474-4422(08)70001-2

Rowe, C. C., Pejoska, S., Mulligan, R. S., Jones, G., Chan, J. G., Svensson, S., et al. (2013). Head-to-head comparison of 11C-PiB and 18F-AZD4694 (NAV4694) for $\beta$-amyloid imaging in aging and dementia. J. Nucl. Med. 54, 880-886. doi: $10.2967 /$ jnumed.112.114785

Sabri, O., Sabbagh, M. N., Seibyl, J., Barthel, H., Akatsu, H., Ouchi, Y., et al. (2015). Florbetaben PET imaging to detect amyloid beta plaques in Alzheimer's disease: phase 3 study. Alzheimers Dement. 11, 964-974. doi: 10.1016/j.jalz.2015.02.004

Saito, T., Mihira, N., Matsuba, Y., Sasaguri, H., Hashimoto, S., Narasimhan, S., et al. (2019). Humanization of the entire murine Mapt gene provides a murine model of pathological human tau propagation. J. Biol. Chem. 294, 12754-12765. doi: 10.1074/jbc.RA119.009487

Sanabria Bohórquez, S., Marik, J., Ogasawara, A., Tinianow, J. N., Gill, H. S., Barret, O., et al. (2019). [(18)F]GTP1 (Genentech Tau Probe 1), a radioligand for detecting neurofibrillary tangle tau pathology in Alzheimer's disease. Eur. J. Nucl. Med. Mol. Imaging 46, 2077-2089. doi: 10.1007/s00259-019-04399-0

Sander, K., Lashley, T., Gami, P., Gendron, T., Lythgoe, M. F., Rohrer, J. D., et al. (2016). Characterization of tau positron emission tomography tracer [(18)F]AV-1451 binding to postmortem tissue in Alzheimer's disease, primary tauopathies, and other dementias. Alzheimers Dement. 12, 1116-1124. doi: 10. 1016/j.jalz.2016.01.003

SantaCruz, K., Lewis, J., Spires, T., Paulson, J., Kotilinek, L., Ingelsson, M., et al. (2005). Tau suppression in a neurodegenerative mouse model improves memory function. Science 309, 476-481. doi: 10.1126/science.1113694

Scheltens, P., De Strooper, B., Kivipelto, M., Holstege, H., Chételat, G., Teunissen, C. E., et al. (2021). Alzheimer's disease. Lancet 397, 1577-1590.

Schmidt, M. E., Janssens, L., Moechars, D., Rombouts, F. J. R., Timmers, M., Barret, O., et al. (2020). Clinical evaluation of [(18)F] JNJ-64326067, a novel candidate PET tracer for the detection of tau pathology in Alzheimer's disease. Eur. J. Nucl. Med. Mol. Imaging 47, 3176-3185. doi: 10.1007/s00259-020-04880-1

Schneider, G. (2018). Automating drug discovery. Nat. Rev. Drug Discov. 17, 97-113. doi: 10.1038/nrd.2017.232

Schöll, M., Wall, A., Thordardottir, S., Ferreira, D., Bogdanovic, N., Långström, B., et al. (2012). Low PiB PET retention in presence of pathologic CSF biomarkers 
in Arctic APP mutation carriers. Neurology 79, 229-236. doi: 10.1212/WNL. 0b013e31825fdf18

Schonhaut, D. R., McMillan, C. T., Spina, S., Dickerson, B. C., Siderowf, A., Devous, M. D. Sr., et al. (2017). (18) F-flortaucipir tau positron emission tomography distinguishes established progressive supranuclear palsy from controls and Parkinson disease: a multicenter study. Ann. Neurol. 82, 622-634. doi: 10.1002/ ana. 25060

Schweighauser, M., Shi, Y., Tarutani, A., Kametani, F., Murzin, A. G., Ghetti, B., et al. (2020). Structures of $\alpha$-synuclein filaments from multiple system atrophy. Nature 585, 464-469.

Sehlin, D., Fang, X. T., Cato, L., Antoni, G., Lannfelt, L., and Syvanen, S. (2016). Antibody-based PET imaging of amyloid beta in mouse models of Alzheimer's disease. Nat. Commun. 7:10759. doi: 10.1038/ncomms10759

Selkoe, D. J., and Hardy, J. (2016). The amyloid hypothesis of Alzheimer's disease at 25 years. EMBO Mol. Med. doi: 10.15252/emmm. 201606210

Sepulcre, J., Grothe, M. J., Sabuncu, M., Chhatwal, J., Schultz, A. P., Hanseeuw, B., et al. (2017). Hierarchical organization of tau and amyloid deposits in the cerebral cortex. JAMA Neurol. 74, 813-820. doi: 10.1001/jamaneurol.2017.0263

Sevigny, J., Chiao, P., Bussière, T., Weinreb, P. H., Williams, L., Maier, M., et al. (2016). The antibody aducanumab reduces $A \beta$ plaques in Alzheimer's disease. Nature 537, 50-56.

Shahnawaz, M., Mukherjee, A., Pritzkow, S., Mendez, N., Rabadia, P., Liu, X., et al. (2020). Discriminating $\alpha$-synuclein strains in Parkinson's disease and multiple system atrophy. Nature 578, 273-277. doi: 10.1038/s41586-020-1984-7

Shankar, G. M., Li, S., Mehta, T. H., Garcia-Munoz, A., Shepardson, N. E., Smith, I., et al. (2008). Amyloid- $\beta$ protein dimers isolated directly from Alzheimer's brains impair synaptic plasticity and memory. Nat. Med. 14, 837-842. doi: $10.1038 / \mathrm{nm} 1782$

Shi, Y., Zhang, W., Yang, Y., Murzin, A. G., Falcon, B., Kotecha, A., et al. (2021b). Structure-based classification of tauopathies. Nature 598, 359-363. doi: 10.1038/ s41586-021-03911-7

Shi, Y., Murzin, A. G., Falcon, B., Epstein, A., Machin, J., Tempest, P., et al. (2021a). Cryo-EM structures of tau filaments from Alzheimer's disease with PET ligand APN-1607. Acta Neuropathol. 141, 697-708. doi: 10.1007/s00401-021-02294-3

Snellman, A., Rokka, J., Lopez-Picon, F. R., Eskola, O., Wilson, I., Farrar, G., et al. (2012). Pharmacokinetics of $\left[{ }^{18} \mathrm{~F}\right]$ flutemetamol in wild-type rodents and its binding to beta amyloid deposits in a mouse model of Alzheimer's disease. Eur. J. Nucl. Med. Mol. Imaging 39, 1784-1795. doi: 10.1007/s00259-012-2178-9

Soto, C., and Pritzkow, S. (2018). Protein misfolding, aggregation, and conformational strains in neurodegenerative diseases. Nat. Neurosci. 21, 1332 1340. doi: 10.1038/s41593-018-0235-9

Spillantini, M. G., and Goedert, M. (2013). Tau pathology and neurodegeneration. Lancet Neurol. 12, 609-622. doi: 10.1016/s1474-4422(13)70090-5

Spires, T. L., Orne, J. D., SantaCruz, K., Pitstick, R., Carlson, G. A., Ashe, K. H., et al. (2006). Region-specific dissociation of neuronal loss and neurofibrillary pathology in a mouse model of tauopathy. Am. J. Pathol. 168, 1598-1607. doi: 10.2353/ajpath.2006.050840

Su, Y., Flores, S., Wang, G., Hornbeck, R. C., Speidel, B., Joseph-Mathurin, N., et al. (2019). Comparison of Pittsburgh compound B and florbetapir in crosssectional and longitudinal studies. Alzheimers Dement. (Amst.) 11, 180-190. doi: 10.1016/j.dadm.2018.12.008

Sun, X., Admane, P., Starosolski, Z. A., Eriksen, J. L., Annapragada, A. V., and Tanifum, E. (2021). Structure-guided design, synthesis, and evaluation of 1indanone and 1,3-indandione derivatives as ligands for misfolded $\alpha$-synuclein aggregates. ChemRxiv [Preprint] doi: 10.26434/chemrxiv.13817243.v1

Sundaram, G. S. M., Dhavale, D. D., Prior, J. L., Yan, P., Cirrito, J., Rath, N. P., et al. (2016). Fluselenamyl: a novel benzoselenazole derivative for PET detection of amyloid plaques $(\mathrm{A} \beta)$ in Alzheimer's disease. Sci. Rep. 6:35636. doi: 10.1038/ srep35636

Tagai, K., Ono, M., Kubota, M., Kitamura, S., Takahata, K., Seki, C., et al. (2020). High-contrast in vivo imaging of tau pathologies in Alzheimer's and nonAlzheimer's disease tauopathies. Neuron 109, 42-58.e8. doi: 10.1016/j.neuron. 2020.09 .042

Teng, E., Kepe, V., Frautschy, S. A., Liu, J., Satyamurthy, N., Yang, F., et al. (2011). [F-18]FDDNP microPET imaging correlates with brain $A \beta$ burden in a transgenic rat model of Alzheimer disease: effects of aging, in vivo blockade, and anti-A $\beta$ antibody treatment. Neurobiol. Dis. 43, 565-575. doi: 10.1016/j. nbd.2011.05.003
Thal, D. R., Beach, T. G., Zanette, M., Heurling, K., Chakrabarty, A., Ismail, A., et al. (2015). $\left[{ }^{18} \mathrm{~F}\right]$ flutemetamol amyloid positron emission tomography in preclinical and symptomatic Alzheimer's disease: specific detection of advanced phases of amyloid- $\beta$ pathology. Alzheimers Dement. 11, 975-985. doi: 10.1016/ j.jalz.2015.05.018

Thal, D. R., Rub, U., Orantes, M., and Braak, H. (2002). Phases of A beta-deposition in the human brain and its relevance for the development of AD. Neurology 58, 1791-1800. doi: 10.1212/wnl.58.12.1791

Uzuegbunam, B. C., Librizzi, D., and Hooshyar Yousefi, B. (2020). PET radiopharmaceuticals for Alzheimer's disease and Parkinson's disease diagnosis, the current and future landscape. Molecules 25:977. doi: 10.3390/molecules 25040977

Uzuegbunam, B. C., Paslawski, W., Zhou, Y., Ågren, H., Längström, B., Weber, W. A., et al. (2021). Optimized disarybisthiazole derivatives with high affinity to alpha-synuclein aggregates and improved pharmacokinetics. Nuklearmedizin 60:144.

Vagenknecht, P., Ono, M., Luzgin, A., Ji, B., Higuchi, M., Noain, D., et al. (2021). Non-invasive imaging of tau-targeted probe uptake by whole brain multispectral optoacoustic tomography. bioRxiv [Preprint]. doi: 10.1101/2021.07.10. 451626

Verdurand, M., Levigoureux, E., Zeinyeh, W., Berthier, L., Mendjel-Herda, M., Cadarossanesaib, F., et al. (2018). In silico, in vitro, and in vivo evaluation of new candidates for $\alpha$-synuclein PET imaging. Mol. Pharm. 15, 3153-3166.

Villemagne, V. L., Mulligan, R. S., Pejoska, S., Ong, K., Jones, G., O’Keefe, G., et al. (2012). Comparison of $11 \mathrm{C}-\mathrm{PiB}$ and $18 \mathrm{~F}$-florbetaben for $\mathrm{A} \beta$ imaging in ageing and Alzheimer's disease. Eur. J. Nucl. Med. Mol. Imaging 39, 983-989. doi: 10.1007/s00259-012-2088-x

Vogel, J. W., Iturria-Medina, Y., Strandberg, O. T., Smith, R., Levitis, E., Evans, A. C., et al. (2020). Spread of pathological tau proteins through communicating neurons in human Alzheimer's disease. Nat. Commun. 11:2612.

Vogel, J. W., Young, A. L., Oxtoby, N. P., Smith, R., Ossenkoppele, R., Strandberg, O. T., et al. (2021). Four distinct trajectories of tau deposition identified in Alzheimer's disease. Nat. Med. 27, 871-881. doi: 10.1038/s41591-021-01309-6

Wagner, J., Ryazanov, S., Leonov, A., Levin, J., Shi, S., Schmidt, F., et al. (2013). Anle138b: a novel oligomer modulator for disease-modifying therapy of neurodegenerative diseases such as prion and Parkinson's disease. Acta Neuropathol. 125, 795-813. doi: 10.1007/s00401-013-1114-9

Walker, Z., Gandolfo, F., Orini, S., Garibotto, V., Agosta, F., Arbizu, J., et al. (2018). Clinical utility of FDG PET in Parkinson's disease and atypical parkinsonism associated with dementia. Eur. J. Nucl. Med. Mol. Imaging 45, 1534-1545. doi: 10.1007/s00259-018-4031-2

Watanabe, H., Kishimoto, T., Kaide, S., Tarumizu, Y., Tatsumi, H., Iikuni, S., et al. (2021). Characterization and optimization of benzimidazopyrimidine and pyridoimidazopyridine derivatives as Tau-SPECT probes. ACS Med. Chem. Lett. 12, 805-811. doi: 10.1021/acsmedchemlett.1c00071

Wegrzynowicz, M., Bar-On, D., Calo', L., Anichtchik, O., Iovino, M., Xia, J., et al. (2019). Depopulation of dense $\alpha$-synuclein aggregates is associated with rescue of dopamine neuron dysfunction and death in a new Parkinson's disease model. Acta Neuropathol. 138, 575-595. doi: 10.1007/s00401-019-02023-x

Wolk, D. A., Sadowsky, C., Safirstein, B., Rinne, J. O., Duara, R., Perry, R., et al. (2018). Use of flutemetamol F 18-labeled positron emission tomography and other biomarkers to assess risk of clinical progression in patients with amnestic mild cognitive impairment. JAMA Neurol. 75, 1114-1123. doi: 10. 1001/jamaneurol.2018.0894

Wolters, E. E., Dodich, A., Boccardi, M., Corre, J., Drzezga, A., Hansson, O., et al. (2021). Clinical validity of increased cortical uptake of [18F]flortaucipir on PET as a biomarker for Alzheimer's disease in the context of a structured 5phase biomarker development framework. Eur. J. Nucl. Med. Mol. Imaging 48, 2097-2109. doi: 10.1007/s00259-020-05118-w

Wren, M. C., Lashley, T., Årstad, E., and Sander, K. (2018). Large inter- and intracase variability of first generation tau PET ligand binding in neurodegenerative dementias. Acta Neuropathol. Commun. 6:34. doi: 10.1186/s40478-018-0 535-z

Xiao, H., Choi, S. R., Zhao, R., Ploessl, K., Alexoff, D., Zhu, L., et al. (2021). A new highly deuterated [18F]AV-45, [18F]D15FSP, for imaging $\beta$-Amyloid plaques in the brain. ACS Med. Chem. Lett. 12, 1086-1092.

Yamasaki, T. R., Holmes, B. B., Furman, J. L., Dhavale, D. D., Su, B. W., Song, E. S., et al. (2019). Parkinson's disease and multiple system atrophy have distinct 
$\alpha$-synuclein seed characteristics. J. Biol. Chem. 294, 1045-1058. doi: 10.1074/jbc. RA118.004471

Yap, S. Y., Frias, B., Wren, M. C., Schöll, M., Fox, N. C., Årstad, E., et al. (2021). Discriminatory ability of next-generation tau PET tracers for Alzheimer's disease. Brain 144:2284-2290. doi: 10.1093/brain/awab120

Yousefi, B. H., Mohring, M., Arzberger, T., Hoglinger, G., Wester, H., and Schwaiger, M. (2016). Novel compounds for specific visualization of alphasynucleinopathies by PET. Eur. J. Nucl. Med. Mol. Imaging 43, S22-S23.

Yousefi, B. H., von Reutern, B., Scherübl, D., Manook, A., Schwaiger, M., Grimmer, T., et al. (2015). FIBT versus florbetaben and PiB: a preclinical comparison study with amyloid-PET in transgenic mice. EJNMMI Res. 5:20. doi: 10.1186/s13550015-0090-6

Yu, L., Cui, J., Padakanti, P. K., Engel, L., Bagchi, D. P., Kotzbauer, P. T., et al. (2012). Synthesis and in vitro evaluation of $\alpha$-synuclein ligands. Bioorg. Med. Chem. 20, 4625-4634. doi: 10.1016/j.bmc.2012.06.023

Zhang, W., Tarutani, A., Newell, K. L., Murzin, A. G., Matsubara, T., Falcon, B., et al. (2020). Novel tau filament fold in corticobasal degeneration. Nature 580, 283-287. doi: 10.1038/s41586-020-2043-0

Zhou, R., Ji, B., Kong, Y., Qin, L., Ren, W., Guan, Y., et al. (2021). PET imaging of neuroinflammation in Alzheimer's disease. Front. Immunol. 12:739130. doi: 10.3389/fimmu.2021.739130
Zhou, Y., Li, J., Nordberg, A., and Ågren, H. (2021). Dissecting the binding profile of PET tracers to corticobasal degeneration tau fibrils. ACS Chem. Neurosci. 12, 3487-3496. doi: 10.1021/acschemneuro.1c00536

Conflict of Interest: The authors declare that the research was conducted in the absence of any commercial or financial relationships that could be construed as a potential conflict of interest.

Publisher's Note: All claims expressed in this article are solely those of the authors and do not necessarily represent those of their affiliated organizations, or those of the publisher, the editors and the reviewers. Any product that may be evaluated in this article, or claim that may be made by its manufacturer, is not guaranteed or endorsed by the publisher.

Copyright (c) $2022 \mathrm{Ni}$ and Nitsch. This is an open-access article distributed under the terms of the Creative Commons Attribution License (CC BY). The use, distribution or reproduction in other forums is permitted, provided the original author(s) and the copyright owner(s) are credited and that the original publication in this journal is cited, in accordance with accepted academic practice. No use, distribution or reproduction is permitted which does not comply with these terms. 